\title{
End of season influenza vaccine effectiveness in adults and children in the United Kingdom in 2017/18
}

Richard Pebody ${ }^{1}$, Abdelmajid Djennad ${ }^{1}$, Joanna Ellis ${ }^{1}$, Nick Andrews ${ }^{1}$, Diogo F P Marques ${ }^{2}$, Simon Cottrell 3 , Arlene J Reynolds ${ }^{2}$, Rory Gunson ${ }^{4}$, Monica Galiano ${ }^{1}$, Katja Hoschler ${ }^{1}$, Angie Lackenby ${ }^{1}$, Chris Robertson ${ }^{5}$, Mark 0’Doherty ${ }^{6}$, Mary Sinnathamby' ${ }^{1}$, Nikolaos Panagiotopoulos ${ }^{1}$, Ivelina Yonova ${ }^{7,8}$, Rebecca Webb7, Catherine Moore ${ }^{3}$, Matthew Donati ${ }^{1}$, Muhammad Sartaj',

Samantha J Shepherd ${ }^{4}$, Jim McMenamin ${ }^{2}$, Simon de Lusignan ${ }^{7,8}$, Maria Zambon $^{1}$

1. Public Health England, United Kingdom

2. Health Protection Scotland, Glasgow, United Kingdom

3. Public Health Wales, Cardiff, United Kingdom

4. West of Scotland Specialist Virology Centre, Glasgow, United Kingdom

5. University of Strathclyde, Glasgow, United Kingdom

6. Public Health Agency Northern Ireland, Belfast, United Kingdom

7. University of Surrey, Guildford, United Kingdom

8. Royal College of General Practitioners, London, United Kingdom

Correspondence: Richard Pebody (Richard.Pebody@phe.gov.uk)

Citation style for this article:

Pebody Richard, Djennad Abdelmajid, Ellis Joanna, Andrews Nick, Marques Diogo F P, Cottrell Simon, Reynolds Arlene J, Gunson Rory, Galiano Monica, Hoschler Katja, Lackenby Angie, Robertson Chris, O’Doherty Mark, Sinnathamby Mary, Panagiotopoulos Nikolaos, Yonova Ivelina, Webb Rebecca, Moore Catherine, Donati Matthew, Sartaj Muhammad, Shepherd Samantha J, McMenamin Jim, de Lusignan Simon, Zambon Maria. End of season influenza vaccine effectiveness in adults and children in the United Kingdom in 2017/18. Euro Surveill. 2019;24(31):pii=1800488. https://doi.org/10.2807/1560-7917.ES.2019.24.31.1800488

Background: In the United Kingdom (UK), in recent influenza seasons, children are offered a quadrivalent live attenuated influenza vaccine (LAIV4), and eligible adults mainly trivalent inactivated vaccine (TIV). Aim: To estimate the UK end-of-season 2017/18 adjusted vaccine effectiveness (aVE) and the seroprevalence in England of antibodies against influenza viruses cultured in eggs or tissue. Methods: This observational study employed the test-negative case-control approach to estimate aVE in primary care. The population-based seroprevalence survey used residual age-stratified samples. Results: Influenza viruses $A\left(\mathrm{H}_{3} \mathrm{~N}_{2}\right)$ (particularly subgroup $\left.{ }_{3} \mathrm{C} .2 \mathrm{a}_{2}\right)$ and $B$ (mainly $B /$ Yamagata/16/88-lineage, similar to the quadrivalent vaccine $B$-virus component but mismatched to TIV) dominated. All-age aVE was $15 \%$ ( $95 \%$ confidence interval (Cl): -6.3 to 32 ) against all influenza; $-16.4 \%(95 \% \mathrm{Cl}:-59.3$ to 14.9$)$ against $\mathrm{A}\left(\mathrm{H}_{3} \mathrm{~N}_{2}\right) ; 24.7 \%$ (95\% Cl: 1.1 to 42.7$)$ against $\mathrm{B}$ and $66.3 \%(95 \% \mathrm{Cl}: 33.4$ to 82.9) against $A\left(\mathrm{H}_{1} \mathrm{~N}_{1}\right)$ pdmo9. For 2-17year olds, LAIV4 aVE was $26.9 \%(95 \% \mathrm{Cl}:-32.6$ to 59.7$)$ against all influenza; $-75.5 \%(95 \% \mathrm{Cl}:-289.6$ to 21 ) against $A\left(\mathrm{H}_{3} \mathrm{~N}_{2}\right) ; 60.8 \%(95 \% \mathrm{Cl}: 8.2$ to 83.3$)$ against $B$ and 90.3\% (95\% Cl: 16.4 to 98.9 ) against $\mathrm{A}\left(\mathrm{H}_{1} \mathrm{~N}_{1}\right)$ pdmo9. For $\geq 18$ year olds, TIV aVE against influenza $B$ was $1.9 \%$ ( $95 \% \mathrm{Cl}:-63.6$ to 41.2$)$. The 2017 seroprevalence of antibody recognising tissue-grown $\mathrm{A}\left(\mathrm{H}_{3} \mathrm{~N}_{2}\right)$ virus was significantly lower than that recognising egg-grown virus in all groups except 15-24 year olds. Conclusions: Overall aVE was low driven by no effectiveness against $A\left(\mathrm{H}_{3} \mathrm{~N}_{2}\right)$ possibly related to vaccine virus egg-adaption and a new $\mathrm{A}\left(\mathrm{H}_{3} \mathrm{~N}_{2}\right)$ subgroup emergence. The TIV was not effective against influenza B. LAIV 4 against influenza $B$ and $A\left(\mathrm{H}_{1} \mathrm{~N}_{1}\right)$ pdmog was effective.

\section{Introduction}

The United Kingdom (UK) has a long-standing selective influenza immunisation programme offering inactivated vaccine to persons $\geq 65$ years of age and those aged 6 months to 64 years of age with an underlying clinical risk factor. Following advice from the Joint Committee of Vaccination and Immunisation (JCVI), the UK started a phased introduction of a universal childhood influenza vaccine programme in 2013/14 [1]. By 2017/18, all children 2-8 years of age across the UK were being offered quadrivalent live attenuated influenza vaccine (LAIV4), with uptake higher than the previous season in targeted cohorts [2]. In addition, in England, besides children 2-8 years of age, all remaining children of primary school age (9-11years of age) in discrete geographical pilots were offered LAIV4. Scotland and Northern Ireland also offered LAIV4 to all children of primary school age (including 9-11 years of age). A B/Yamagata lineage virus (B/Phuket/3073/2013-like virus) and a B/ Victoria lineage virus (B/Brisbane/60/2008-like virus) were contained in the season's quadrivalent inactivated influenza vaccine (QIV) and LAIV 4 , but not in the trivalent inactivated influenza vaccine (TIV), which contained only the B/Victoria lineage vaccine virus [3].

Several areas of concern in relation to vaccine effectiveness (VE) have emerged in recent seasons. Firstly, although the UK has found evidence of relatively good LAIV VE and continues to recommend its preferential use [4], in the United States (US) where there has 


\section{FIGURE 1}

Swabbing results of patients with influenza-like illness in primary care in the United Kingdom, October 2017-April 2018 $(n=3,992$ patients swabbed $)$

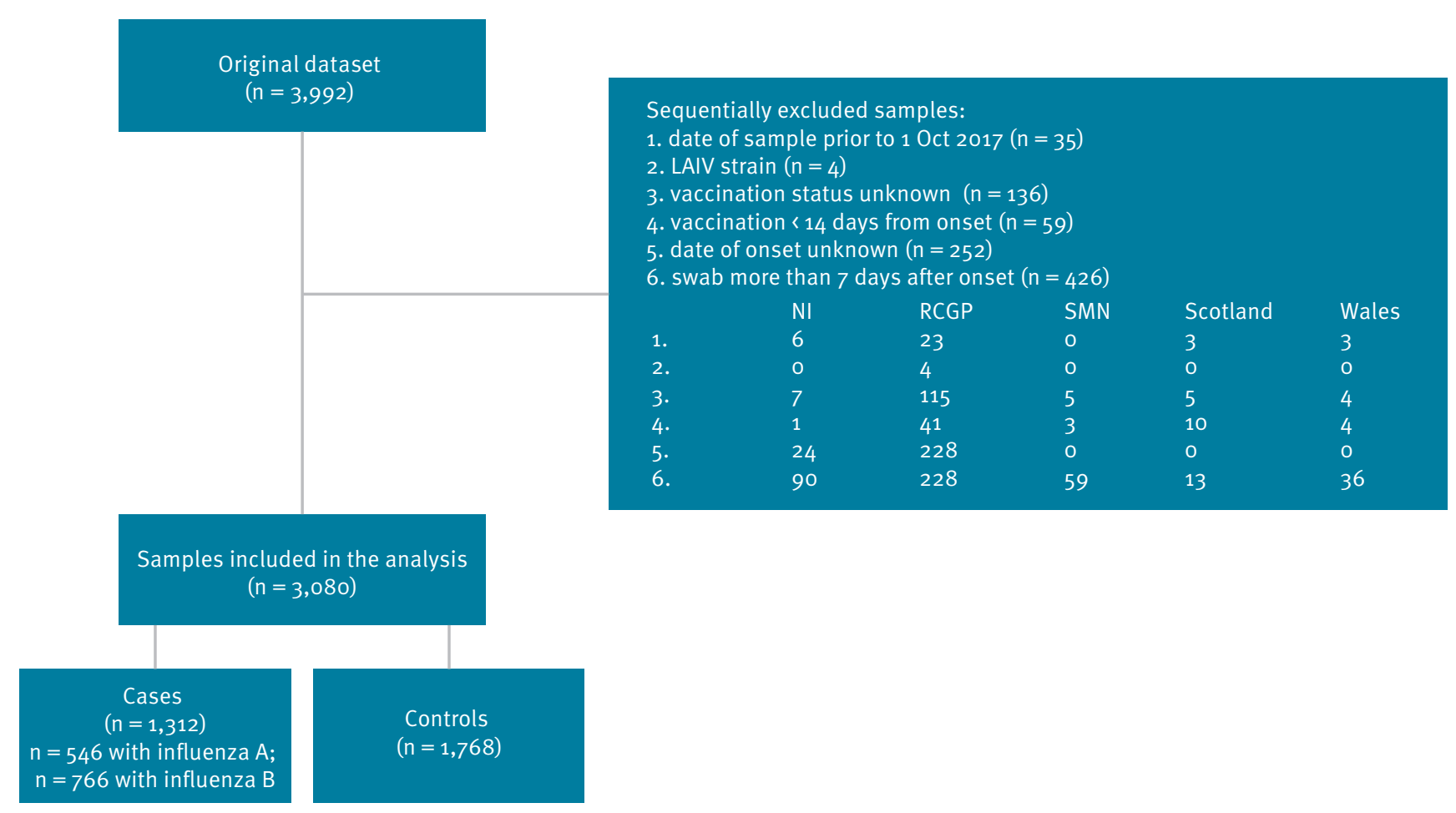

LAIV4: quadrivalent live attenuated influenza vaccine; NI: Northern Ireland national sentinel scheme; RCGP: Royal College of General Practitioners' Research and Surveillance Centre; SMN: Public Health England Specialist Microbiology Network.

been a longstanding paediatric influenza vaccination programme using both LAIV and inactivated influenza vaccine (IIV), reduced LAIV VE against influenza $\mathrm{A}\left(\mathrm{H}_{1} \mathrm{~N}_{1}\right)$ pdmog was reported by the US Centers for Disease Control and Prevention (CDC) [5]. This led to a recommendation from the Advisory Committee on Immunization Practice (ACIP) that LAIV should not be used in the US from 2016 until 2018. Questions were raised about what might explain these observations, such as reduced replicative ability of the $\mathrm{A}\left(\mathrm{H}_{1} \mathrm{~N}_{1}\right)$ pdmo9 strain [6]. Secondly, reductions in IIV VE particularly in older persons, a highly vaccinated population in the UK, have been previously noted, particularly against influenza $A\left(\mathrm{H}_{3} \mathrm{~N}_{2}\right)$, with several explanations proffered, including egg adaption of vaccine viruses, which may affect their antigenicity [7]. Finally, the majority of vaccinated adults at clinical risk were receiving TIV rather than QIV in the UK programme. Mismatches of the vaccine $B$-lineage virus compared with the predominant circulating influenza B virus lineage have been reported, which raises questions on the optimal vaccine to use in influenza vaccine programmes [4].

The 2017/18 influenza season in the UK was characterised by the co-circulation of both influenza $A\left(\mathrm{H}_{3} \mathrm{~N}_{2}\right)$ and influenza $B$, with some circulation of $A\left(\mathrm{H}_{1} \mathrm{~N}_{1}\right)$ pdmo9. A large number of respiratory outbreaks in highly vaccinated populations were reported, particularly in long-term care facilities. In addition, increased admissions to hospital and excess mortality especially among older adult age groups were noted despite vaccine uptake levels of $>70 \%$ in $\geq 65$ year olds [8]. The UK has a well-established system to monitor influenza VE each season based upon sentinel swabbing in primary care [9]. This paper presents the end-of-season 2017/18 VE findings for laboratory-confirmed infection in primary care across all age groups, with a focus on $\mathrm{LAIV}_{4}$ in children and IIV in adult age groups.

\section{Methods}

\section{Design of the study}

The test-negative case-control (TNCC) design was used to estimate VE, with the study undertaken in the registered population of five sentinel general practice surveillance networks across the UK, all of which undertake respiratory swabbing according to a standard protocol. Details of these schemes have been outlined previously [4]. The five sentinel schemes are: the Royal College of General Practitioners (RCGP) Research and Surveillance Centre (RSC) network, the Public Health England (PHE) Specialist Microbiology Network (SMN) and the national sentinel schemes of Northern Ireland, Scotland and Wales. 
TABLE 1

Characteristics of influenza A and B cases and controls, United Kingdom, October 2017-April $2018(\mathrm{n}=3,080)$

\begin{tabular}{|c|c|c|c|c|c|c|c|}
\hline \multirow{2}{*}{ Characteristics } & \multirow{2}{*}{$\begin{array}{l}\text { Control } \\
(n=1,768)\end{array}$} & \multicolumn{4}{|c|}{$\begin{array}{l}\text { Cases by influenza type (and subtype if known) } \\
\qquad(\mathrm{n}=1,315)^{\mathrm{a}}\end{array}$} & \multirow{2}{*}{ Total } & \multirow{2}{*}{$p$ value } \\
\hline & & $\begin{array}{c}B \\
(n=766)\end{array}$ & $\begin{array}{l}A\left(\mathrm{H}_{1} \mathrm{~N}_{1}\right) \\
(\mathrm{n}=96)\end{array}$ & $\begin{array}{l}A\left(\mathrm{H}_{3} \mathrm{~N}_{2}\right) \\
(n=431)\end{array}$ & $\begin{array}{c}\text { A (unknown) } \\
(n=22)\end{array}$ & & \\
\hline \multicolumn{8}{|l|}{ Age in years } \\
\hline $0-1$ & 153 & 7 & 7 & 8 & 0 & 175 & \multirow{7}{*}{$<0.0001$} \\
\hline $2-11$ & 212 & 71 & 22 & 58 & 0 & 363 & \\
\hline $12-17$ & 98 & 66 & 5 & 28 & 4 & 201 & \\
\hline $18-44$ & 587 & 267 & 31 & 143 & 7 & 1,035 & \\
\hline $45-64$ & 447 & 261 & 22 & 122 & 10 & 862 & \\
\hline$\geq 65$ & 270 & 94 & 9 & 72 & 1 & 446 & \\
\hline Missing & 1 & 0 & 0 & 0 & 0 & 1 & \\
\hline \multicolumn{8}{|l|}{ Sex } \\
\hline Female & 1,083 & 416 & 49 & 247 & 14 & 1,809 & \multirow{3}{*}{0.004} \\
\hline Male & 671 & 346 & 47 & 184 & 8 & 1,256 & \\
\hline Missing & 14 & 4 & 0 & 0 & 0 & 18 & \\
\hline \multicolumn{8}{|l|}{ Database } \\
\hline Northern Ireland & 99 & 85 & 6 & 66 & 8 & 264 & \multirow{5}{*}{$<0.0001$} \\
\hline RCGP & 1,203 & 484 & 76 & 189 & 0 & 1,952 & \\
\hline SMN & 86 & 51 & 6 & 16 & 4 & 163 & \\
\hline Scotland & 266 & 79 & 5 & 135 & 10 & 495 & \\
\hline Wales & 114 & 67 & 3 & 25 & 0 & 209 & \\
\hline \multicolumn{8}{|l|}{ Risk group } \\
\hline No & 1,075 & 553 & 62 & 258 & 11 & 1,959 & \multirow{3}{*}{$<0.0001$} \\
\hline Yes & 545 & 139 & 25 & 137 & 7 & 853 & \\
\hline Missing & 148 & 74 & 9 & 36 & 4 & 271 & \\
\hline \multicolumn{8}{|l|}{ Onset to swab in days } \\
\hline $0-1$ & 240 & 78 & 13 & 85 & 5 & 421 & \multirow{3}{*}{$<0.0001$} \\
\hline $2-4$ & 867 & 458 & 59 & 252 & 10 & 1,646 & \\
\hline $5-7$ & 661 & 230 & 24 & 94 & 7 & 1,016 & \\
\hline \multicolumn{8}{|l|}{ Vaccination status } \\
\hline Unvaccinated & 1,273 & 594 & 78 & 280 & 18 & 2,243 & \multirow{3}{*}{$<0.0001$} \\
\hline Vaccinated (14-91 days ago) & 297 & 75 & 10 & 78 & 2 & 462 & \\
\hline Vaccinated (>91 days ago) & 198 & 97 & 8 & 73 & 2 & 378 & \\
\hline \multicolumn{8}{|l|}{ Month of event } \\
\hline October & 270 & 2 & 0 & 4 & 2 & 278 & \multirow{7}{*}{$<0.0001$} \\
\hline November & 310 & 27 & 4 & 18 & 2 & 361 & \\
\hline December & 344 & 169 & 19 & 125 & 4 & 661 & \\
\hline January & 509 & 374 & 39 & 167 & 10 & 1,099 & \\
\hline February & 206 & 147 & 24 & 67 & 3 & 447 & \\
\hline March & 110 & 45 & 8 & 48 & 1 & 212 & \\
\hline April & 19 & 2 & 2 & 2 & 0 & 25 & \\
\hline \multicolumn{8}{|c|}{ Pilot area (SMN and RCGP RSC only) } \\
\hline No & 1,391 & 599 & 84 & 226 & 3 & 2,303 & \multirow{2}{*}{$<0.0001$} \\
\hline Yes & 377 & 167 & 12 & 205 & 19 & 780 & \\
\hline \multicolumn{8}{|c|}{ Vaccination status (for 2-17 year olds only) } \\
\hline Unvaccinated & 252 & 127 & 26 & 62 & 4 & 471 & \\
\hline Injection (QIV) & 9 & 1 & 0 & 1 & 0 & 11 & 0.52 \\
\hline Intranasal/LAIV4 & 49 & 9 & 1 & 23 & o & 82 & \\
\hline
\end{tabular}

LAIV4: quadrivalent live attenuated influenza vaccine; QIV: quadrivalent inactivated influenza vaccine; RCGP RSC: Royal College of General Practitioners' Research and Surveillance Centre scheme; SMN: Public Health England Specialist Microbiology Network.

a While the study comprised 1,312 cases of influenza, 1,315 are presented in the table, because there were two cases of infection with multiple types or subtypes. One of these cases was infected by influenza $A\left(\mathrm{H}_{1} \mathrm{~N}_{1}\right)$ pdmog and, in addition $\mathrm{A}\left(\mathrm{H}_{3} \mathrm{~N}_{2}\right)$ and $B$ (thus accounting, for two additional cases in the total number of cases by type/subtype) and the other was infected by $\mathrm{A}\left(\mathrm{H}_{1} \mathrm{~N}_{1}\right)$ pdmog and also $\mathrm{A}\left(\mathrm{H}_{3} \mathrm{~N}_{2}\right)$ (thus accounting for one additional case in the total number of cases by type/subtype).

A total of 149 samples had date of vaccination imputed. 


\section{TABLE 2}

Details of vaccination status for key demographic and clinical variables, United Kingdom, October 2017-April 2018 $(\mathrm{n}=3,080)$

\begin{tabular}{|c|c|c|c|c|}
\hline Characteristics & $\begin{array}{l}\text { Not vaccinated } \\
\qquad(n=2,242)\end{array}$ & $\begin{array}{l}\text { Vaccinated } \\
\qquad(n=838)\end{array}$ & Total & $p$ value \\
\hline \multicolumn{5}{|l|}{ Age in years } \\
\hline$<2$ & 172 & 3 & 175 & \multirow{6}{*}{$<0.0001$} \\
\hline $2-11$ & 270 & 93 & 363 & \\
\hline $12-17$ & 187 & 14 & 201 & \\
\hline $45-64$ & 619 & 243 & 862 & \\
\hline$\geq 65$ & 108 & 336 & 444 & \\
\hline Missing & 0 & 1 & 1 & \\
\hline \multicolumn{5}{|l|}{ Sex } \\
\hline Female & 1,279 & 527 & 1,806 & \multirow{3}{*}{0.004} \\
\hline Male & 948 & 308 & 1,256 & \\
\hline Missing & 15 & 3 & 18 & \\
\hline \multicolumn{5}{|l|}{ Surveillance scheme } \\
\hline Northern Ireland & 206 & 58 & 264 & \multirow{5}{*}{0.002} \\
\hline RCGP RSC & 1,380 & 571 & 1,951 & \\
\hline SMN & 116 & 47 & 163 & \\
\hline Scotland & 371 & 122 & 493 & \\
\hline Wales & 169 & 40 & 209 & \\
\hline \multicolumn{5}{|l|}{ Risk group } \\
\hline No & 1,665 & 294 & 1,959 & \multirow{3}{*}{$<0.0001$} \\
\hline Yes & 376 & 474 & 850 & \\
\hline Missing & 201 & 70 & 271 & \\
\hline \multicolumn{5}{|l|}{ Onset to swab in days } \\
\hline $5-7$ & 742 & 274 & 1,016 & 0.49 \\
\hline \multicolumn{5}{|c|}{ Pilot area (RCGP RSC and SMN only) } \\
\hline No & 1,650 & 652 & 2,302 & \multirow{2}{*}{0.014} \\
\hline Yes & 592 & 186 & 778 & \\
\hline \multicolumn{5}{|l|}{ Month of event } \\
\hline October & 244 & 34 & 278 & \multirow{7}{*}{$<0.0001$} \\
\hline November & 290 & 69 & 359 & \\
\hline December & 478 & 183 & 661 & \\
\hline January & 773 & 326 & 1,099 & \\
\hline February & 309 & 138 & 447 & \\
\hline March & 136 & 75 & 211 & \\
\hline April & 12 & 13 & 25 & \\
\hline \multicolumn{5}{|c|}{ Cases infected with strains characterised by sequencing/phylogenetic analysis } \\
\hline \multicolumn{5}{|c|}{ Influenza A } \\
\hline $\mathrm{H}_{3} \mathrm{~N}_{2}-3 \mathrm{C} .2 \mathrm{a} 3-$ subgroup 2 & 1 & 1 & 2 & \multirow{7}{*}{0.02} \\
\hline $\mathrm{H}_{3} \mathrm{~N}_{2}-3 \mathrm{C} .2 \mathrm{a}_{2}-$ subgroup 3 & 49 & 64 & 113 & \\
\hline $\mathrm{H}_{3} \mathrm{~N}_{2}-3 \mathrm{C} .2 \mathrm{a}-$ subgroup NA & 1 & 0 & 1 & \\
\hline $\mathrm{H}_{3} \mathrm{~N}_{2}-3 \mathrm{C} .2 \mathrm{a} 1 \mathrm{a}-$ subgroup 4 & 3 & 0 & 3 & \\
\hline $\mathrm{H}_{3} \mathrm{~N}_{2}-3 \mathrm{C} .2 \mathrm{a} 1 \mathrm{~b}-$ subgroup 5 & 18 & 7 & 25 & \\
\hline $\mathrm{H}_{3} \mathrm{~N}_{2}-{ }_{3} \mathrm{C} .2 \mathrm{a}_{1}$ - subgroup NA & 8 & 3 & 11 & \\
\hline $\mathrm{H}_{3} \mathrm{~N}_{2}-3 \mathrm{C} .3 \mathrm{a}$ & 4 & 3 & 7 & \\
\hline $\mathrm{H}_{1} \mathrm{~N}_{1}-6 \mathrm{~B} .1$ clade & 35 & 12 & 47 & $\mathrm{~N} / \mathrm{A}$ \\
\hline \multicolumn{5}{|l|}{ Influenza B } \\
\hline B/Yamagata & 300 & 106 & 406 & 0.26 \\
\hline
\end{tabular}

RCGP RSC: Royal College of General Practitioners' Research and Surveillance Centre scheme; SMN: Public Health England Specialist Microbiology Network. 
The study took place from 1 October 2017 - when respiratory swabbing was started - until 15 April 2018. The study population was patients presenting to their general practitioner (GP) during the study period with an acute influenza-like illness (ILI), who the GP obtained consent from and swabbed during the consultation. A case of ILI was defined as an individual who presented with an acute respiratory illness with physiciandiagnosed fever or complaint of feverishness in the previous 7 days [9]. The combination of acute onset, cough and systemic symptoms (fever, headache, myalgia etc.) was recommended as a guide to diagnosis. Participating GPs were asked to invite persons presenting with ILI to provide a swab for diagnosis, with swabbing undertaken regardless of vaccination status. Cases were patients who tested positive for seasonal influenza A or B virus by real-time PCR. Controls were patients with the same symptoms who tested negative for influenza A or B virus.

During the consultation, the GP completed a standard questionnaire. This collected demographic (age and sex), clinical (date of onset and history of fever) and epidemiological information from patients including vaccination status. Vaccine history, including date of vaccination was obtained mainly from patient records. Vaccine type (LAIV4-intranasal; IIV injectable) was specified on the form. Additional information was collected for those $\geq 18$ years of age on whether vaccination was with QIV or TIV. Persons in the study were categorised according to Department of Health defined risk categories for influenza vaccination [2]. High risk was determined by the presence of well recognised risk morbidities recorded in the electronic health record for the patient concerned [2]. In addition, it was noted whether the general practice was in a pilot area for England-based paediatric immunisation schemes, where all primary school age children were offered LAIV4 vaccine.

Patients were defined as vaccinated if they were reported to have received the $2017 / 18$ seasonal vaccine at least 14 days before first onset of symptoms. Patients were excluded if they were vaccinated less than 14 days before symptom onset. If date of vaccination was unknown it was assumed to be $15 / 10 / 2017$, which was the median of all known vaccination dates this season: the approach used in prior seasons [4]. Registered patients were excluded if they (or their parent/guardian) had expressed a wish to be; or the practice used one of the codes that indicate the patient may not want to share data (e.g. no consent for electronic record sharing). The opt out of sharing data was $2.25 \%$.

\section{Detection and characterisation of influenza} viruses in sentinel-surveillance- and nonsentinel samples

Combined throat and nose swabs taken from GPs are sent from the sentinel GP surveillance networks to their usual laboratory. Influenza laboratory confirmation was undertaken using comparable real-time $P C R$ methods able to detect circulating influenza $A$ and $B$ viruses [10]. All laboratories sent influenza virus positive samples to the reference laboratories for further characterisation.

Isolation of Influenza viruses was attempted from all suitable PCR positive samples, from both sentinel GP practices and also non-sentinel schemes using MadinDarby canine kidney epithelial (MDCK) cells or MDCK cells containing the cDNA of human 2,6-sialtransferase (SIAT1) cells $[11,12]$.

Virus isolates with a haemagglutination titre $\geq 40$ were characterised antigenically using post-infection ferret antisera in haemagglutination inhibition ( $\mathrm{HI}$ ) assays, with guinea pig $\left(\mathrm{A}_{3} \mathrm{H}_{3} \mathrm{~N}_{2}\right)$ viruses) or turkey (influenza $B$ viruses) red blood cells [12]. Reference virus strains used for $\mathrm{HI}$ assays included 2017/18 vaccine strains [3] and other $A\left(\mathrm{H}_{3} \mathrm{~N}_{2}\right)$ and influenza $B$ reference strains grown in embryonated chicken eggs and tissue culture cells.

Nucleotide sequencing of the haemagglutinin ( $\mathrm{HA})$ gene of a subset of influenza $A\left(\mathrm{H}_{3} \mathrm{~N}_{2}\right)$ and influenza $B$ viruses selected to be representative of the range of the patients' age, date of sample collection, geographical location and antigenic characterisation of the virus isolate, if performed, was undertaken. Phylogenetic trees of the $\mathrm{HA}$ gene of $\mathrm{A}\left(\mathrm{H}_{3} \mathrm{~N}_{2}\right)$ and influenza $B$ viruses were constructed with a neighbour-joining algorithm available in the Molecular Evolutionary Genetics Analysis (MEGA) 7 software (http://www.megasoftware.net) [13].

HA sequences from reference strains used in the phylogenetic analysis were obtained from the EpiFlu database of the Global Initiative on Sharing All Influenza Data (GISAID) (www.gisaid.org) (Supplement). The HA sequences generated for this study and used in the phylogenetic analysis, were deposited in GISAID under the following accession numbers: $A\left(\mathrm{H}_{3} \mathrm{~N}_{2}\right)$ viruses: EPl1112284, EPl1112292, EPI1112308, EPI1112348, EPl1112444, EPl1112484, EPl1112492, EPl1112500, EPl1112532, EPl1112596, EPl1112612, EPI1112620, EPl1112636, EPl1112652, EPl1112782, EPl1112788, EPl1139067, EPl1139075, EPl1139123, EPI1139155, EPl1139339, EPl1139347, EPl1139379, EPI1139490, EPl1139578, EPl1139646, EPl1139681, EPI1144477, EPl1144533, EPl1144549, EPI1144573, EPI1144589, EPl1144613, EPl1144661, EPI1144701, EPI1144709, EPl1144725, EPl1144845, EPl1144885, EPI1144925, EPl1144957, EPl1144965, EPI1144997, EPI1152027, EPI1152059, EPI1152227, EPI1152251, EPI1152275, EPl1152291, EPl1152451, EPI1152507, EPl1152623, EPl1152631, EPl1152687, EPI1152695, EPI1152711, EPI1152734, EPI1152736, EPI1152756, EPI1173388, EPl1173668, EPl1173700, EPI1173732, EPI1173756, EPl1173789, EPl1173979, EPl1173993, EPI1173999, EPI1174019; influenza B viruses: EPI1112540, EPl1112572, EPl1112580, EPl1112765, EPI1112790, 


\section{FIGURE 2}

Phylogenetic analysis of the haemagglutinin sequences of influenza A(H3N2) viruses detected in the United Kingdom, July 2017-April 2018

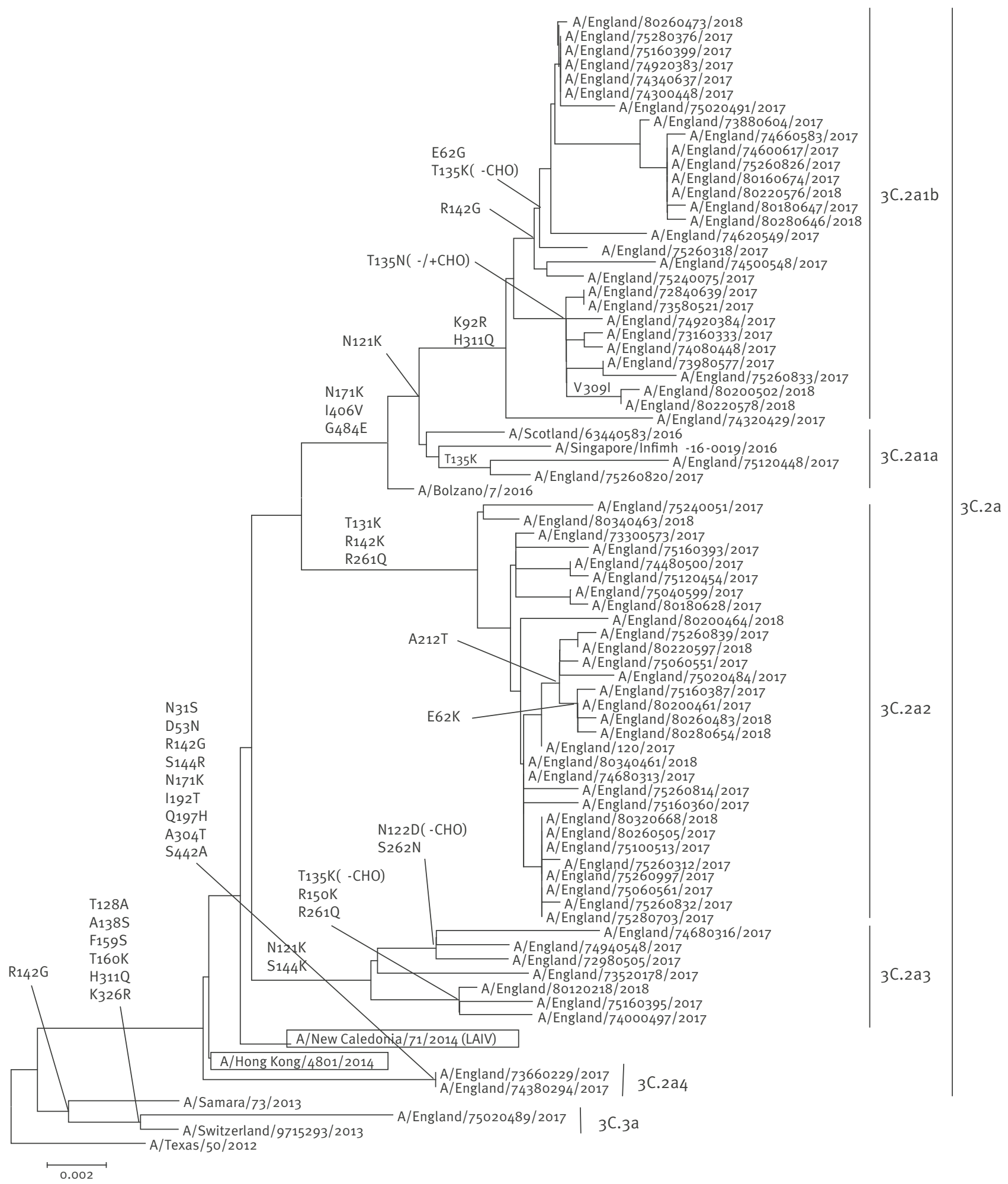

LAIV: live attenuated influenza vaccine ; QIV: quadrivalent inactivated influenza vaccine; TIV: trivalent inactivated influenza vaccine.

a The sequences are obtained from all sources (i.e. sentinel surveillance and non-sentinel schemes) so some of the sequences are from as early as July 2017

The $\mathrm{H}_{3}$ haemagglutinin sequences obtained in England in 2017 and 2018 are depicted on the tree. The vaccine strains (A/

HongKong/4801/2014 for TIV and QIV; A/NewCaledonia/71/2014 for LAIV) are boxed; reference viruses are represented in italics. Amino acid substitutions are depicted at the nodes. '-/+CHO' indicates the addition or deletion of a potential glycosylation site. The names of the subclades and clusters to which the sequences belong to are indicated on the right hand side of the tree. The scale is proportional to number of nucleotide substitutions per site. 
Frequency of H3N2 haemagglutinin genetic groups by month, England, September 2017-April $2018(\mathrm{n}=605)^{\prime}$
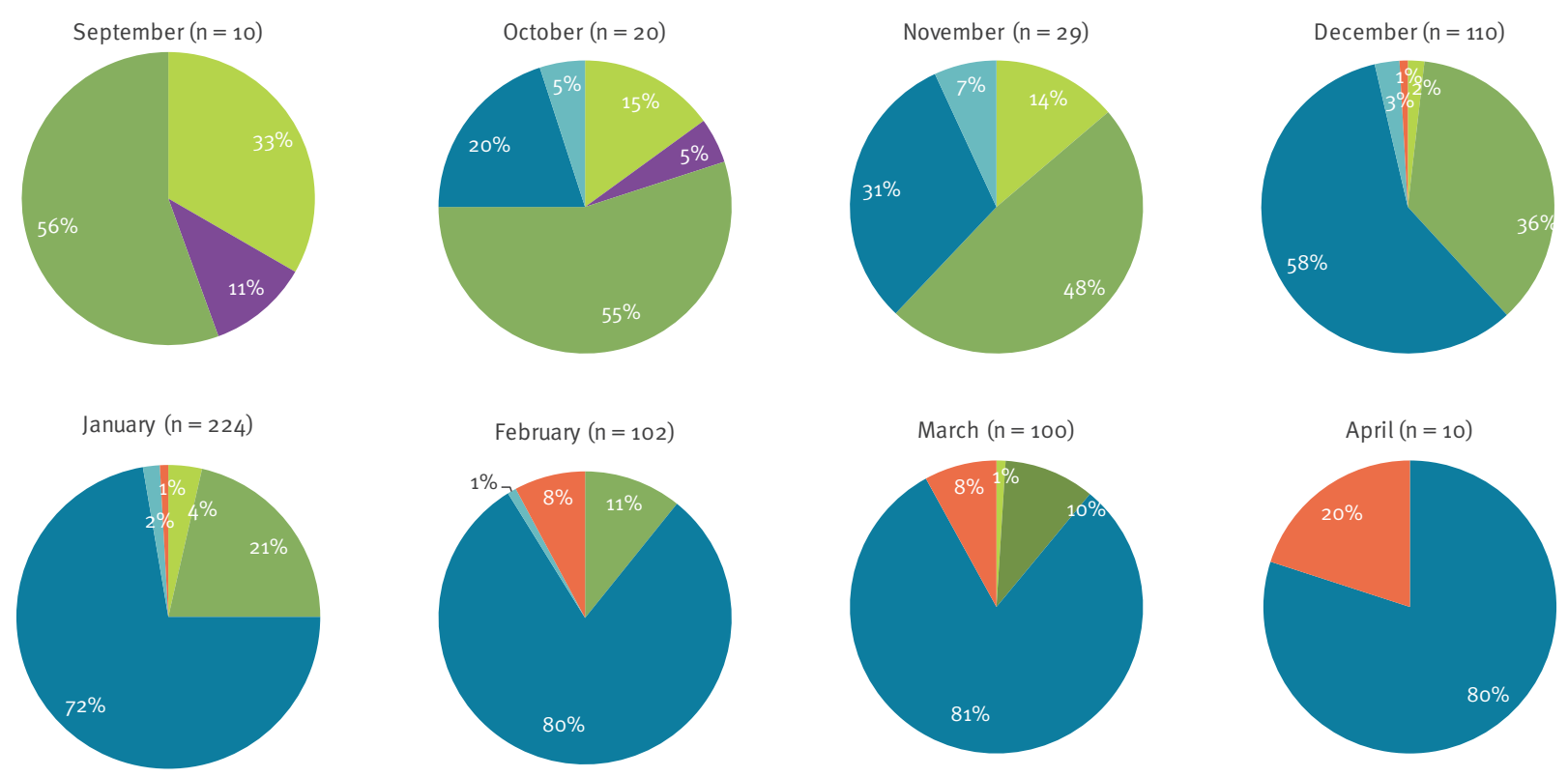

$$
\begin{aligned}
& 3 \mathrm{C}_{2 \mathrm{a}} \text { (subgroup 2) 3C2a } 4 \text { (subgroup 1) 3C2a1b (subgroup 5) } \\
& \text { 3C2a2 (subgroup 3) 3C2a1 (subgroup 4) 3С } \quad \text { 3С }
\end{aligned}
$$

Genetic groups definition as suggested by NextFlu/Crick Feb 2018 (in brackets, previous definition suggested by NextFlu/ECDC Sept 2017).

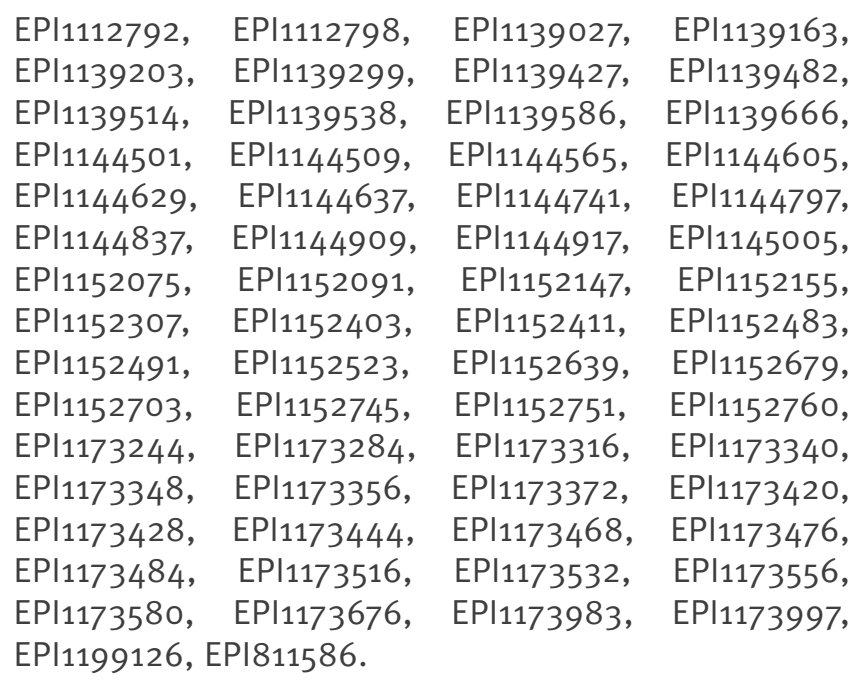

\section{Seroepidemiological survey}

Annual sero-surveys were carried out in England using residual sera collected and submitted to the PHE Sero-epidemiology Unit (SEU) during the 2016 and 2017 summers. The PHE SEU archive is an opportunistic collection of residual serum samples from routine microbiological testing, submitted voluntarily each year from laboratories throughout England, with samples anonymised and permanently unlinked from any patient identifying information with only age, sex, date of collection and contributing laboratory retained. A total of 780 residual sera from the SEU were collected during the 2017 summer period (after the previous and before start of the current influenza season) and 1,000 samples in summer 2016. Samples were randomly selected with constraints to provide an even distribution by age and region. The sample size was chosen to enable reasonable precision of estimates (95\% confidence interval $(\mathrm{Cl})$ width less than $+/-10 \%)$ within each age group.

Laboratory analysis was focused on detection of antibody to influenza $A\left(\mathrm{H}_{3} \mathrm{~N}_{2}\right)$ and $B /$ Yamagata viruses. Serum samples were analysed for presence of $A\left(\mathrm{H}_{3} \mathrm{~N}_{2}\right)$ antibody to representative seasonal influenza strains as indicated by the vaccine composition for 2017/18 using guinea pig erythrocytes for $\mathrm{A}\left(\mathrm{H}_{3} \mathrm{~N}_{2}\right)$ and turkey erythrocytes for influenza $B$ as previously described. Antigen was grown in eggs and tissue culture (MDCK cells) to examine the issue of potential egg adaptation and the influenza B antigen diethyl-ether extracted.

Sera were analysed in single titrations in 96-well format by performing doubling serum dilutions starting at $1: 10$ up to $1: 1,280$, with virus input adjusted to 4 haemagglutination forming units (4 HAU). 


\section{FIGURE 4}

Phylogenetic analysis of the haemagglutinin sequences of influenza B viruses detected in the United Kingdom, July 2017April 2018

B/Yamagata lineage

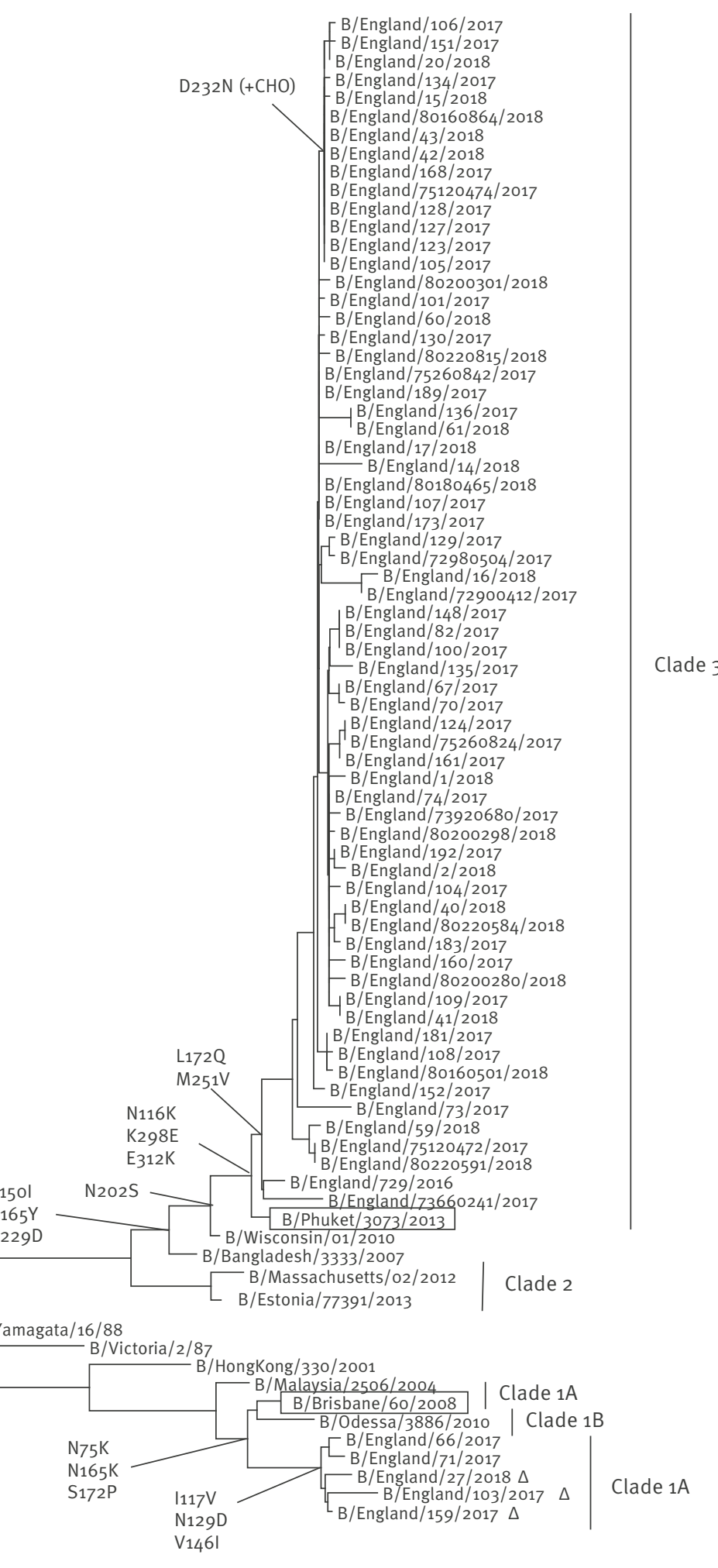

LAIV: live attenuated influenza vaccine; QIV: quadrivalent inactivated influenza vaccine; TIV: trivalent inactivated influenza vaccine.

a The sequences are obtained from all sources (i.e. sentinel surveillance and non-sentinel schemes) so some of the sequences are from as early as July 2017 .

The influenza B haemagglutinin sequences obtained in England in 2017 and 2018 are depicted on the tree. The vaccine strains (B/

Brisbane/60/2008 for TIV, QIV and LAIV; B/Phuket/3073/2013 for QIV and LAIV) are boxed; reference viruses are represented in italics. Amino acid substitutions are depicted at the nodes. ' $+\mathrm{CHO}$ ' indicates the addition of a potential glycosylation site. The names of the clades to which the sequences belong to are indicated on the right hand side of the tree. The scale is proportional to number of nucleotide substitutions per site. 


\section{TABLE 3}

Vaccine effectiveness estimates for influenza by subtype, clade, age group and vaccine type, United Kingdom, October 2017-April $2018(\mathrm{n}=3,080)$

\section{Characteristics \\ Cases \\ Controls \\ Crude VE \\ Adjustedc VE \\ Vaccinated \\ Unvaccinated \\ Vaccinated ${ }^{\mathrm{b}}$ \\ Unvaccinated \\ $(95 \% \mathrm{Cl})$ \\ $(95 \% \mathrm{Cl})$}

Influenza A and B, by age group in years and vaccine type for 2-17 year olds

\begin{tabular}{|l|c|c|c|c|c|c|}
\hline All age & 343 & 969 & 495 & 1,273 & $9.0(-6.9$ to 22.5$)$ & $15.0(-6.3$ to 32.0$)$ \\
\hline $2-17$ (QIV) & 2 & 213 & 9 & 244 & NR & NR \\
\hline $2-17$ (LAIV4) & 33 & 213 & 49 & 244 & $22.9(-24.4$ to 52.2$)$ & $26.9(-32.6$ to 59.7$)$ \\
\hline $18-64$ & 166 & 696 & 225 & 809 & $14.2(-7.4$ to 31.5$)$ & $12.2(-16.8$ to 34.0$)$ \\
\hline$\geq 65$ & 136 & 38 & 201 & 70 & $-24.6(-95.7$ to 20.6$)$ & $10.1(-54.8$ to 47.8$)$ \\
\hline
\end{tabular}

Influenza A by age group in years and vaccine type for 2-17 year olds

\begin{tabular}{|l|c|c|c|c|c|c|}
\hline All age & 172 & 375 & 495 & 1,273 & $-18.0(-45.3$ to 4.2$)$ & $4.5(-27.4$ to 28.5$)$ \\
\hline $2-17$ (QIV) & 1 & 86 & 9 & 244 & NR & $-39.0(-140.1$ to 19.6$)$ \\
\hline $2-17$ (LAIV4) & 24 & 86 & 49 & 244 & $-1.8(-108.1$ to 50.2$)$ \\
\hline $18-64$ & 76 & 258 & 225 & 809 & $-5.9(-42.3$ to 21.2$)$ & $4.4(-39.9$ to 34.6$)$ \\
\hline$\geq 65$ & 65 & 16 & 201 & 70 & $-41.5(-160.6$ to 23.2$)$ & $10.3(-82.1$ to 55.8$)$ \\
\hline
\end{tabular}

Influenza $\mathrm{A}\left(\mathrm{H}_{3} \mathrm{~N}_{2}\right)$ by age group in years and vaccine type for 2-17 year olds

\begin{tabular}{|l|c|c|c|c|c|c|}
\hline All age & 151 & 280 & 495 & 1,273 & $-38.7(-73.4$ to -10.9$)$ & $-16.4(-59.3$ to 14.9$)$ \\
\hline $2-17$ (QIV) & 1 & 59 & 9 & 244 & NR \\
\hline $2-17$ (LAIV4) & 23 & 59 & 49 & 244 & $-94.1(-243.7$ to & $-9.6)$ \\
\hline $18-64$ & 67 & 198 & 225 & 809 & $-21.7(-66.5$ to 11.1$)$ & $-14.7(-72.7$ to 23.8$)$ \\
\hline$\geq 65$ & 57 & 15 & 201 & 70 & $-32.3(-148.6$ to 29.6$)$ & $16.8(-74.2$ to 60.3$)$ \\
\hline
\end{tabular}

Influenza $\mathrm{A}\left(\mathrm{H}_{1} \mathrm{~N}_{1}\right)$ pdmog by age group in years and vaccine type for 2-17 year olds

\begin{tabular}{|l|c|c|c|c|c|c|}
\hline All age & 18 & 78 & 495 & 1,273 & $40.7(-0.1$ to 64.8) & $66.3(33.4$ to 82.9) \\
\hline $2-17$ (QIV) & 0 & 23 & 9 & 244 & NR & NR \\
\hline $2-17($ LAIV4) & 1 & 23 & 49 & 244 & $78.3(-64.1$ to 97.1) & $90.3(16.4$ to 98.9) \\
\hline $18-64$ & 6 & 47 & 225 & 809 & $54.1(-8.7$ to 80.6) & $69.1(11.4$ to 89.2$)$ \\
\hline$\geq 65$ & 8 & 1 & 201 & 70 & NR & NR \\
\hline
\end{tabular}

Influenza B by age group in years and type of vaccine

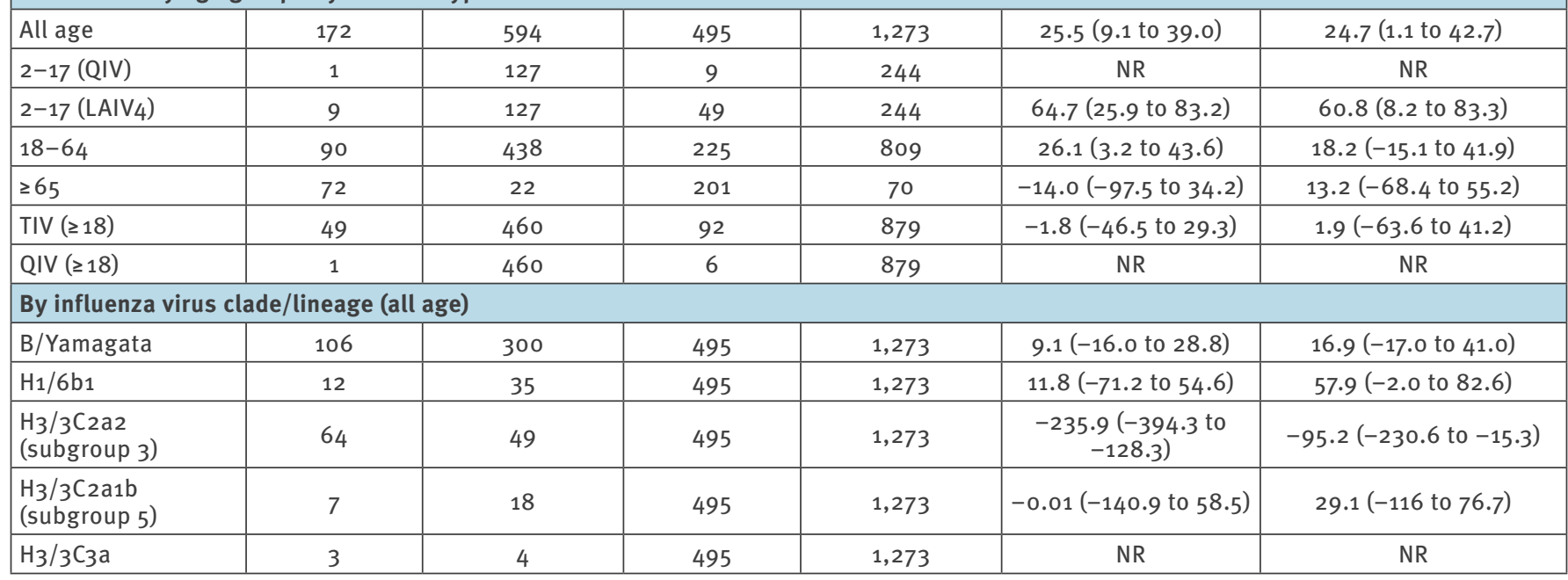

$\mathrm{CI}$ : confidence interval; LAIV4: quadrivalent live attenuated influenza vaccine; NR: not reported; QIV: quadrivalent inactivated vaccine; TIV: trivalent inactivated vaccine; VE: vaccine effectiveness.

a Six vaccinated cases aged between 2-17years (three infected with influenza $\mathrm{A}\left(\mathrm{H}_{3} \mathrm{~N}_{2}\right)$ and three infected with $\mathrm{A}\left(\mathrm{H}_{1} \mathrm{~N}_{1}\right)$ pdmog) had no information on the type of vaccine (QIV or TIV) they received, so they are not included in the analyses presented in the table.

${ }^{b}$ Eight vaccinated controls aged between 2-17years had no information on the type of vaccine (QIV or TIV) they received, so they are not included in the analyses presented in the table.

c Adjusted for age group, risk-group, sex, month, pilot area and surveillance scheme. 


\section{Statistical methods}

The swabbing results were analysed using a testnegative design for VE. The odds ratio (OR) of being vaccinated between cases and controls was used to calculate the crude VE as (1 - OR) x 100\%. We performed a multivariable logistic regression, as previously [4], to adjust VE for potential confounders with influenza laboratory results as the outcome and influenza vaccination status as the linear predictor. Estimates were calculated adjusting for age (by<2, 2-11, 12-17, 18-44, 45-64 and $\geq 65$ years age groups), month of onset of symptoms, surveillance scheme, risk-group, sex, and residence in an area where a primary school programme was in place. Stratification was by age $2-17$, 18-64 and $\geq 65$ years and was split by vaccine type: LAIV4/QIV within those aged 2-17years and QIV/TIV for those aged $\geq 18$ years. The effect of prior season vaccination was also described by calculating all the VEs (vaccinated both 2017/18 and 2016/17, only 2016/17 and only 2017/18) and comparing to not vaccinated in either season. Decline in VE was assessed by stratification in the model by time since vaccination (vaccinated within 3 months of onset and $\geq 3$ months before onset), and also by stratification by month of onset (October-December/January-April). To minimise inclusion of underpowered results, VE estimates where the upper and lower $95 \% \mathrm{Cl}$ respectively extended below $-50 \%$ and above $80 \%$ were excluded.

Sensitivity analyses were undertaken - specifically including all swabs no matter how long after onset they had been taken; then a model including those vaccinated within 14 days as unvaccinated.

For statistical analysis of the seroprevalence data, serum titres below the detection limit (<10) were assigned a numeric value of five, while sera above the previously determined threshold titre $\geq 40$ were considered seropositive for the purpose of analysis and all available titres were transformed into $\log _{2}$ titres. Proportions with positive titres with $95 \% \mathrm{Cl}$ by age group are presented. To compare $\mathrm{A}\left(\mathrm{H}_{3} \mathrm{~N}_{2}\right)$ proportions positive for antigen grown in tissue culture compared with egg, McNemar's chi-squared test for paired data was used on those samples tested by both assays.

\section{Ethical statement}

The collection of sera in the PHE SEU archive has undergone ethical review (REC reference: 05/Q0505/45). The collection and analysis of swab forms according to positivity was undertaken as part of routine influenza surveillance, with swab test-results relayed back to sentinel GPs to assist in clinical management. The collection of the clinical data accords with routine usual practice in public health. Specific ethical approval was not necessary.

\section{Results}

\section{Characteristics of study patients}

During the study, 3,992 persons were sampled in the participating sentinel primary care practices and were tested. A total of 912 samples were excluded: the reasons for study exclusion are summarised in Figure 1, with swabbing more than 7 days after onset the main explanation. Four samples were excluded as LAIV vaccine virus was detected. The details of the 3,080 samples remaining stratified according to the swab result and by vaccination are described in Tables 1 and 2. A total of 149 samples had date of vaccination imputed. There were 1,768 controls and 1,312 cases, of whom 546 were influenza $\mathrm{A}\left(431 \mathrm{H}_{3} \mathrm{~N}_{2}, 22 \mathrm{~A}\right.$ unknown and 96 $\left(\mathrm{H}_{1} \mathrm{~N}_{1}\right)$ pdmo9, and 766 were influenza $B$, with a small number of multiple infections (two cases).

\section{Influenza strains detected during the 2017/18 season}

Figure 2 shows the phylogenetic analysis of the $\mathrm{HA}$ sequences for $\mathrm{A}\left(\mathrm{H}_{3} \mathrm{~N}_{2}\right)$ 2017/18 viruses. Genetic characterisation of $778 \mathrm{~A}\left(\mathrm{H}_{3} \mathrm{~N}_{2}\right)$ influenza viruses from all sources (i.e. sentinel surveillance and non-sentinel schemes) since week 40 showed that the majority (747; 96\%) belong to HA genetic subclade 3C.2a, with 199 (27\%) of these 747 viruses belonging to a cluster within this genetic subclade designated as 3 C.2a1, and the others belonging to other clusters in $3 \mathrm{C} .2 \mathrm{a}$, designated as $3 \mathrm{C} .2 \mathrm{a} 2,3 \mathrm{C} .2 \mathrm{a} 3$ and $3 \mathrm{C} .2 \mathrm{a} 4$. The remaining $31 \mathrm{~A}\left(\mathrm{H}_{3} \mathrm{~N}_{2}\right)$ viruses (4\%) fell in $\mathrm{HA}$ subclade $3 \mathrm{C} .3 \mathrm{a}$. The northern hemisphere 2017/18 influenza $A\left(\mathrm{H}_{3} \mathrm{~N}_{2}\right)$ vaccine strain $A / H o n g K o n g / 4801 / 2014$ belonged in genetic subclade 3 C.2a and its relatedness to the circulating strains is shown in Figure 2.

The emergence of subgroups and temporal differences in the distribution of viruses within both $3 \mathrm{C} .2 \mathrm{a}$ and ${ }_{3}$ C.2a1 has been observed over the season in viruses from all sources (Figure 3). Early in the season during October and November, viruses in 3 C.2a1, belonging mainly in subgroup 3 C.2a1b (clade 5) accounted for $55-60 \%$ of the $A\left(\mathrm{H}_{3} \mathrm{~N}_{2}\right)$ viruses from all sources characterised genetically. During December 2017 to April 2018 , the proportion of viruses belonging to the subclade 3 C.2a2 (subgroup 3 ) become the dominant circulating $\mathrm{A}\left(\mathrm{H}_{3} \mathrm{~N}_{2}\right)$ subgroup by the end of the season. This season's $A\left(\mathrm{H}_{3} \mathrm{~N}_{2}\right)$ viruses were again difficult to type by $\mathrm{HI}$ analysis with ferret antisera, and only 24 influenza $A\left(\mathrm{H}_{3} \mathrm{~N}_{2}\right)$ viruses from all sources were antigenically characterised since week 40 2017, representing a minority of the detections and thus a potential bias in the available antigenic data. The viruses antigenically analysed showed better reactivity to ferret antiserum raised to tissue culture grown A/HongKong/4801/2014 virus, than with antiserum derived from egg propagated A/HongKong/4801/2014 virus. All 24 antigenically characterised viruses were also genetically characterised, with 15 belonging in genetic group 3 C.2a, including 10 within 3 C.2a2 (subgroup 3 ) and five 
TABLE 4

Adjusted vaccine effectiveness estimates for influenza $\mathrm{A}(\mathrm{H} 3 \mathrm{~N} 2)$ by prior vaccination status and subtype in children

$2-17$ years of age (LAIV only) and adults $\geq 18$ years, United Kingdom, October 2017-April $2018(\mathrm{n}=1,888)$

\begin{tabular}{|l|c|c|c|}
\hline Vaccination status & Cases & Controls & Adjusted ${ }^{\mathrm{a}}$ VE (95\% CI) \\
\hline 2-17year olds (LAIV only) & 49 & 196 & Reference \\
\hline Unvaccinated in 2016/17 and 2017/18 & 5 & 33 & NR \\
\hline Vaccinated only in 2016/17 & 10 & 20 & $-139.9(-615.1$ to 19.5$)$ \\
\hline Vaccinated only in 2017/18 & 11 & 20 & $-61.8(-372$ to 44.5) \\
\hline Vaccinated in 2016/17 and 2017/18 & 189 & 743 & Reference \\
\hline$\geq 18$ year olds & 16 & 96 & $12.9(-68.3$ to 55.0) \\
\hline Unvaccinated in 2016/17 and 2017/18 & 20 & 76 & $-2.6(-85.8$ to 43.4) \\
\hline Vaccinated only in 2016/17 & 94 & 310 & $-9.3(-64.8$ to 27.5) \\
\hline Vaccinated only in 2017/18 & &
\end{tabular}

$\mathrm{Cl}$ : confidence interval; LAIV: live attenuated influenza vaccine; NR: not reported; VE: vaccine effectiveness.

adjusted for age group, risk-group, sex, month, pilot area and surveillance scheme.

in $3 \mathrm{C} .2 \mathrm{a}_{1}$ (subgroup 4 ) and nine $\mathrm{H}_{3} \mathrm{~N}_{2}$ isolates belonging in subclade 3 C.3a.

Genetic characterisation of 688 influenza B viruses from all sources was completed. A total of 682 (99\%) viruses were classified as belonging to the B/ Yamagata/16/88-lineage, genetically similar to $B /$ Phuket/3073/2013, the influenza B/Yamagata/16/88lineage component of 2017/18 northern hemisphere quadrivalent vaccine [14]. Six (1\%) were classified as falling in the $\mathrm{B} / \mathrm{Victoria} / 2 / 87$-lineage; genetically similar to B/Brisbane/60/2008 (the influenza B/ Victoria/2/87-lineage component of 2017/18 northern hemisphere trivalent and quadrivalent vaccines [14]) falling within genetic clade $1 \mathrm{~A}$, but with five of these belonging within a subgroup in clade $1 \mathrm{~A}$ characterised by deletion of two amino acids in the HA. The relationship of the HA genes of the circulating strains analysed compared with the vaccine strains is shown in Figure 4. A total of 489 influenza B viruses were isolated and antigenically characterised since week 40 2017; 485 (99\%) viruses were characterised as belonging to the $\mathrm{B} /$ Yamagata/16/88-lineage and antigenically similar to $\mathrm{B} /$ Phuket/3073/2013. Of the viruses characterised as belonging to the $B / V i c t o r i a / 2 / 87$-lineage, one virus was antigenically similar to B/Brisbane/60/2008, with the double deletion subgroup viruses characterised as antigenically distinct from B/Brisbane/60/2008.

\section{Model fitting for vaccine effectiveness estimation}

When estimating VE, age group, sex, time period (defined by month of sample collection), surveillance scheme, risk group and primary school age pilot programme area were adjusted for in a multivariable logistic regression model. All variables that were adjusted for were significantly associated with a positive swab (Table 1). The number and proportion vaccinated for these variables are shown in Table 2. Only age, month of onset and risk-factor were confounders for the vaccine effects (changing the overall estimate by more than $5 \%)$.

The crude and adjusted VE estimates against all influenza, influenza $A\left(\mathrm{H}_{3} \mathrm{~N}_{2}\right)$, influenza $A\left(\mathrm{H}_{1} \mathrm{~N}_{1}\right)$ pdmog and $B$ are shown in Table 3. For any influenza ( $A$ or $B$ ), the crude VE for all ages was $9.0 \%$; the adjusted VE point estimate of influenza vaccine against any laboratoryconfirmed infection was $15.0 \%(95 \% \mathrm{Cl}:-6.3$ to 32.0$)$. Further sensitivity analyses were undertaken. Firstly, including all swabs no matter how long after onset they had been taken made less than $3 \%$ difference to the overall VE point estimate. Then a model including those vaccinated within 14 days as unvaccinated and including all swabs regardless of time since onset of symptoms found again $<3 \%$ difference to the VE point estimate.

\section{Influenza $\mathrm{A}(\mathrm{H} 3 \mathrm{~N} 2)$}

The all-age adjusted VE was $-16.4 \%(95 \% \mathrm{Cl}:-59.3$ to 14.9) for $\mathrm{A}\left(\mathrm{H}_{3} \mathrm{~N}_{2}\right)$ (Table 3). Examining clade- and lineage-specific estimates demonstrated overlapping $\mathrm{Cls}$ (Table 3).

Vaccine effectiveness in adults

Table 3 shows the adjusted VE against influenza $\mathrm{A}\left(\mathrm{H}_{3} \mathrm{~N}_{2}\right)$ for inactivated vaccine (IIV) in 18-64year olds $(-14.7 \%$; $95 \% \mathrm{Cl}:-72.7$ to 23.8$)$ and $\geq 65$ year olds (16.8\%; $95 \% \mathrm{Cl}:-74.2$ to 60.3 ) with no evidence of significant effectiveness in either group. In relation to vaccination in the prior season in those $\geq 18$ years of age (Table 4), the VE point estimate were low in all strata and differences were non-significant ( $p$ value $=0.69)$.

Vaccine effectiveness in children

The crude and adjusted VE against $A\left(\mathrm{H}_{3} \mathrm{~N}_{2}\right)$ in children 2-17years of age for LAIV4 is shown in Table 3 with no evidence of significant effectiveness. There 
were sparse data to undertake analysis of VE for QIV in children. Table 4 shows the influence of LAIV4 vaccination in 2-17year olds in the prior season, the differences were non-significant ( $p$ value $=0.17$ ).

\section{Influenza $\mathrm{A}(\mathrm{H} 1 \mathrm{N1})$ pdm09}

The adjusted VE was $66.3 \%$ ( $95 \% \mathrm{Cl}: 33.4$ to 82.9 ) for $\mathrm{A}\left(\mathrm{H}_{1} \mathrm{~N}_{1}\right)$ pdmog for all ages (Table 3$)$.

Vaccine effectiveness in adults

Table 3 shows an adjusted VE against $\mathrm{A}\left(\mathrm{H}_{1} \mathrm{~N}_{1}\right)$ pdmo9 for inactivated vaccine (IIV) in $18-64$ year olds of $69.1 \%$ (95\% Cl: 11.4 to 89.2 ).

\section{Vaccine effectiveness in children}

The adjusted VE against $\mathrm{A}\left(\mathrm{H}_{1} \mathrm{~N}_{1}\right)$ pdmog in 2-17year olds for LAIV4 (Table 3) was $90.3 \%(95 \% \mathrm{Cl}: 16.4$ to 98.9). There were sparse data to undertake analysis of VE for QIV in children or according to prior season vaccine history in adults and children.

\section{Influenza B}

The overall all-age adjusted VE estimate against influenza B was $24.7 \%$ (95\% Cl: 1.1 to 42.7 ) (Table 3), compared with $16.9 \%(95 \% \mathrm{Cl}:-17.0$ to 41.0$)$ against only B/Yamagata/16/88-lineage (Table 3).

\section{Vaccine effectiveness in adults}

The adjusted VE against influenza B for 18-64 years olds for IIV (Table 3) was $18.2 \% \quad(95 \% \mathrm{Cl}$ : -15.1 to 41.9) and was $13.2 \%$ (95\% Cl: -68.4 to 55.2$)$ for those $\geq 65$ years of age. Statistically significant protection was not seen in either age group. There were sparse data to undertake analysis of VE for QIV in adults, though effectiveness against TIV only was low at $1.9 \%$ ( $95 \% \mathrm{Cl}:-63.6$ to 41.2 ) (Table 3 ). In relation to vaccination in the prior season in those $\geq 18$ years of age (Table 5), the adjusted VE estimates were similar regardless of prior vaccine history.

Vaccine effectiveness in children

The adjusted VE against influenza $B$ in children 2-17years of age for LAIV4 was $60.8 \%(95 \% \mathrm{Cl}: 8.2$ to 83.3) (Table 3). Table 5 shows the influence of prior season $\mathrm{LAIV}_{4}$ vaccination in 2-17year olds on influenza B. The VE point estimate was high and similar regardless of prior season vaccine history.

\section{Vaccine effectiveness by time since vaccination and period}

Table 6 shows the adjusted VE by time since vaccination and period. No significant difference was observed for influenza $B, A\left(\mathrm{H}_{3} \mathrm{~N}_{2}\right)$ or $\mathrm{A}\left(\mathrm{H}_{1} \mathrm{~N}_{1}\right)$ pdmog.

\section{Detection of antibody in population serum samples}

Antibody prevalence levels to A/Hong Kong/4801/2014 virus were highest in the youngest ( 15 years and 15-24year-old) age groups for egg-grown virus for samples taken in summer 2017. Although egg-grown $\mathrm{A}\left(\mathrm{H}_{3} \mathrm{~N}_{2}\right)$ ('vaccine-like' virus) antibody levels were lower for 25-64year olds, they were relatively higher in those aged $\geq 65$ years old (Figure $5 \mathrm{~A}$ ) - which is the most highly vaccinated population. The pattern was similar for samples taken in summer 2016. Overall the 2017 seroprevalence was lower for $A\left(\mathrm{H}_{3} \mathrm{~N}_{2}\right)$ viruses grown in tissue culture compared with egg-grown across all age groups, with the mean differences by age group statistically significant in all ages except 15-24 year olds (Figure $5 \mathrm{~A}$ ). The difference in seropositivity proportions between the two laboratory assays (tissue culture minus egg-grown) and their corresponding $\mathrm{Cls}$ and $p$ values for the same age groups are given as: $<15$ years olds: $-13 \%$ ( $95 \% \mathrm{Cl}:-19 \%$ to $-7 \%, \mathrm{p}<0.001)$; $15-24$ years old: $-11 \%(-23 \%$ to $1 \%, p=0.09) ; 25-44$ years old: $-11 \%(-20 \%$ to $-2 \%, p=0.02) ; 45-64$ years old: $-15 \%(-22 \%$ to $-7 \%, p<0.001)$; $\geq 65$ years old: $-24 \%(-32 \%$ to $-15 \%, p<0.001)$.

\section{Discussion}

This study finds overall a low influenza VE during a season that saw co-circulation of influenza $B$ with a B-lineage mismatch comparing to trivalent vaccine and influenza $\mathrm{A}\left(\mathrm{H}_{3} \mathrm{~N}_{2}\right)$ with a new dominant genetic subgroup. We demonstrate significant effectiveness against influenza $B$ in children who received the quadrivalent influenza vaccine, but poor effectiveness against influenza B in adults, particularly those who received trivalent vaccine. No significant $V E$ against $A\left(\mathrm{H}_{3} \mathrm{~N}_{2}\right)$ was seen in either adults or children regardless of whether vaccine was live attenuated or inactivated. A number of variants of $\mathrm{A}\left(\mathrm{H}_{3} \mathrm{~N}_{2}\right)$ circulated during the course of the winter, with subgroups present at the start of the season gradually being replaced by different subgroups later. There was evidence of reduced population immunity to tissue-culture-adapted $A\left(H_{3} N_{2}\right)$ vaccine virus, which is more representative of the World Health Organization (WHO) recommended vaccine virus compared to egg-propagated virus [15]. Finally, we found good protection against influenza $\mathrm{A}\left(\mathrm{H}_{1} \mathrm{~N}_{1}\right)$ pdmog in both adults and children, especially in those who had received live attenuated influenza vaccine.

There are several potential strengths to this study. The test-negative case-control design which is used, is a well-established approach to measure influenza VE in the UK as in many other countries. We used our standard method to provide comparability to previous season's UK VE estimates. In addition, we triangulated VE and population seroprevalence data to provide important insights into the underlying explanations for this season's observations. There are some limitations to the study; in particular only small numbers of children, contraindicated LAIV, had received QIV with consequent inability to provide reliable VE estimates for this group. Due to limited circulation, only limited VE estimates for $A\left(\mathrm{H}_{1} \mathrm{~N}_{1}\right)$ pdmog could be confidently undertaken. Date of vaccination had to be imputed for some records. This is unlikely to have led to a large amount of misclassification as influenza circulation started after the majority of influenza vaccination had been 


\section{TABLE 5}

Adjusted vaccine effectiveness estimates for influenza B by prior vaccine status and subtype in children 2-17 years of age (LAIV4 only) and adults $\geq 18$ years, United Kingdom, October 2017-April 2018 ( $\mathrm{n}=2,184$ )

\begin{tabular}{|c|c|c|c|}
\hline Vaccination status & Cases & Controls & Adjusted $^{\mathrm{a}}$ VE $(95 \% \mathrm{Cl})$ \\
\hline \multicolumn{4}{|l|}{ 2-17 year olds (LAIV only) } \\
\hline Unvaccinated in $2016 / 17$ and $2017 / 18$ & 115 & 196 & Reference \\
\hline Vaccinated only in $2016 / 17$ & 2 & 33 & $72.5(-33.8$ to 94.3$)$ \\
\hline Vaccinated only in $2017 / 18$ & 4 & 20 & NR \\
\hline Vaccinated in $2016 / 17$ and $2017 / 18$ & 2 & 20 & $81.6(10.9$ to 96.2$)$ \\
\hline \multicolumn{4}{|l|}{$\geq 18$ year olds } \\
\hline Unvaccinated in $2016 / 17$ and $2017 / 18$ & 411 & 743 & Reference \\
\hline Vaccinated only in $2016 / 17$ & 15 & 96 & $40.0(-13.0$ to 68.1$)$ \\
\hline Vaccinated only in $2017 / 18$ & 24 & 76 & $35.3(-10.8$ to 62.3$)$ \\
\hline Vaccinated in $2016 / 17$ and $2017 / 18$ & 117 & 310 & $12.1(-24.6$ to 38.0$)$ \\
\hline
\end{tabular}

$\mathrm{Cl}$ : confidence interval; LAIV: live attenuated influenza vaccine; NR: not reported; VE: vaccine effectiveness.

${ }^{a}$ Adjusted for age group, risk-group, sex, month, pilot area and surveillance scheme.

completed by the end of November. The only patients that misclassification has a non-negligible chance of occurring for are those with onset in October $(n=9)$ or November $(n=11)$ with missing vaccination date. This is a very small proportion of the total numbers vaccinated.

The end-of-season VE estimation against all laboratory-confirmed influenza illness presenting in primary care found poor effectiveness, also in adults. The results, which are driven by the dominance of $A\left(\mathrm{H}_{3} \mathrm{~N}_{2}\right)$ and $B$ are consistent with the mid- and end-of-season 2017/18 VE estimates published elsewhere in Europe and North America, many of whom experienced seasons with circulation of $\mathrm{A}\left(\mathrm{H}_{3} \mathrm{~N}_{2}\right)$ [16-18]. Our findings of reduced $V E$ against influenza $B$ are discordant with a number of other settings in Europe and North America [16-18]. This observation of reduced VE is likely to be due to several factors.

Notably the $2017 / 18$ season in the UK saw early circulation of influenza $B$ with a lineage mismatch to the 2017/18 trivalent vaccine, where influenza B cases observed in the UK were mainly due to viruses belonging to the B/Yamagata lineage, with only a small proportion of $B / V i c t o r i a$ lineage viruses detected [8]. There was evidence of good protection against influenza $B$ in children who received the $\mathrm{LAIV}_{4}$ vaccine. However, poor effectiveness against influenza B was observed in adults, particularly when restricted to those vaccinated persons who had received the 2017/18 TIV. Unfortunately, there were sparse data to calculate a reliable VE estimate for QIV only. Our finding of poor TIV effectiveness against influenza $B$ in adults is consistent with the epidemiology seen in the UK in 2017/18, with large numbers of influenza B cases hospitalised in highly vaccinated populations such as $\geq 65$ year olds [8]. Our results were inconsistent with some studies elsewhere in Europe and Canada that did suggest a degree of cross-protection even though there was circulation of a lineage mismatch influenza B virus. These latter observations may be due to prior infection or vaccination with a $\mathrm{B} /$ Yamagata lineage virus in earlier seasons [19]. Although we were unable to estimate QIV effectiveness in adults, some published data do demonstrate superior effectiveness and cost-effectiveness of QIV compared with TIV $[20,21]$. More recent modelling by PHE based on this work has been conducted to understand the potential incremental benefit of QIV in adults in the presence of the UK childhood LAIV4 programme [22]. This work found that, once the programme in children of primary school age is fully established, there is still benefit from preferentially using QIV in at risk adults $<65$ years of age, including pregnant women.

We found no evidence of significant effectiveness against influenza $\mathrm{A}\left(\mathrm{H}_{3} \mathrm{~N}_{2}\right)$ with either inactivated or live attenuated influenza vaccine, all of which are manufactured on eggs. As the season progressed the majority of $A\left(H_{3} \mathrm{~N}_{2}\right)$ viruses that were genetically characterised shifted from genetic subclade 3 C.2a1b (subgroup 5) to subclade 3 C.2a2 (subgroup 3) which comprised the majority of $\mathrm{A}\left(\mathrm{H}_{3} \mathrm{~N}_{2}\right)$ vaccine failures observed this season. This compares to the 2016/17 UK influenza season that was also dominated by $\mathrm{A}\left(\mathrm{H}_{3} \mathrm{~N}_{2}\right)$ though mainly of the 3 C.2a1 subclade, where although effectiveness in the elderly was poor, there was still evidence by the end of the season of significant effectiveness of LAIV4 against $\mathrm{A}\left(\mathrm{H}_{3} \mathrm{~N}_{2}\right)$ in children and of moderate protection in young adults [23]. Such evidence of poorer VE against $\mathrm{A}\left(\mathrm{H}_{3} \mathrm{~N}_{2}\right)$, has been well recognised in recent seasons $[24,25]$. This is a complex and multifactorial problem. The $A\left(\mathrm{H}_{3} \mathrm{~N}_{2}\right)$ vaccine virus component has not changed between 2016/17 and 2017/18, and our results suggest that the divergence in results between the two seasons may be due to several factors including changes in the dominant circulating genetic subgroup. It is not possible to conclude if these genetic changes were 
TABLE 6

Adjusted vaccine effectiveness estimates for influenza by influenza subtype and time since vaccination and period, United Kingdom, October 2017-April $2018(\mathrm{n}=3,080)$

\begin{tabular}{|c|c|c|c|c|c|}
\hline \multirow{2}{*}{$\begin{array}{l}\text { Time elapsed since vaccination at } \\
\text { symptom onset or period of symptom } \\
\text { onset }\end{array}$} & \multicolumn{2}{|c|}{ Cases } & \multicolumn{2}{|c|}{ Controls } & \multirow{2}{*}{$\begin{array}{l}\text { Adjusted }^{a} \text { VE } \\
\qquad(95 \% \mathrm{Cl})\end{array}$} \\
\hline & Vaccinated & Unvaccinated & Vaccinated & Unvaccinated & \\
\hline \multicolumn{6}{|l|}{ Influenza A and B } \\
\hline 3 months & 163 & 969 & 297 & 1,273 & $18.7(-7.7$ to 38.6$)$ \\
\hline$\geq 3$ months & 180 & 969 & 198 & 1,273 & $10.4(-19.9$ to 33.0$)$ \\
\hline Oct to Dec & 83 & 291 & 203 & 721 & $-7.3(-65.4$ to 30.4$)$ \\
\hline Jan to Apr & 260 & 678 & 292 & 552 & $20.3(-3.9$ to 38.9$)$ \\
\hline \multicolumn{6}{|l|}{ Influenza A } \\
\hline 3 months & 89 & 375 & 297 & 1,273 & $-1.3(-44.7$ to 29.1$)$ \\
\hline$\geq 3$ months & 83 & 375 & 198 & 1,273 & $9.5(-32.4$ to 38.1$)$ \\
\hline Oct to Dec & 48 & 129 & 203 & 721 & $-43.4(-157.0$ to 20.0$)$ \\
\hline Jan to Apr & 124 & 246 & 292 & 552 & $14.9(-19.8$ to 39.5$)$ \\
\hline \multicolumn{6}{|l|}{ Influenza $\mathrm{A}\left(\mathrm{H}_{3} \mathrm{~N}_{2}\right)$} \\
\hline 3 months & 78 & 280 & 297 & 1,273 & $-17.6(-73.7$ to 20.4$)$ \\
\hline$\geq 3$ months & 73 & 280 & 198 & 1,273 & $-15.4(-73.4$ to 23.2$)$ \\
\hline Oct to Dec & 44 & 103 & 203 & 721 & $-71.0(-227.4$ to 10.7$)$ \\
\hline Jan to Apr & 107 & 177 & 292 & 552 & $-3.6(-49.7$ to 28.3$)$ \\
\hline \multicolumn{6}{|l|}{ Influenza H1N1pdmog } \\
\hline 3 months & 10 & 78 & 297 & 1,273 & $47.9(-15.1$ to 76.5$)$ \\
\hline$\geq 3$ months & 8 & 78 & 198 & 1,273 & $78.8(40.2$ to 92.5$)$ \\
\hline Oct to Dec & 4 & 19 & 203 & 721 & NR \\
\hline Jan to Apr & 14 & 59 & 292 & 552 & $71.7(36.8$ to 87.4$)$ \\
\hline \multicolumn{6}{|l|}{ Influenza B } \\
\hline 3 months & 75 & 594 & 297 & 1,273 & $33.5(5.2$ to 53.4$)$ \\
\hline$\geq 3$ months & 97 & 594 & 198 & 1,273 & $16.1(-18.8$ to 40.8$)$ \\
\hline Oct to Dec & 36 & 162 & 203 & 721 & $19.3(-40.3$ to 53.6$)$ \\
\hline Jan to Apr & 136 & 432 & 292 & 552 & $25.9(-1.8$ to 46.0$)$ \\
\hline
\end{tabular}

$\mathrm{Cl}$ : confidence interval; NR: not reported; VE: vaccine effectivenesS

adjusted for age group, risk-group, sex, month, pilot area and surveillance scheme.

significant antigenically. The analyses used to characterise $\mathrm{H}_{3} \mathrm{~N}_{2}$ circulating strains are limited as a result of the receptor binding changes in the viruses which have occurred over recent years [26]. Such changes have altered the ability to use the traditional tools for antigenic characterisation of circulating strains using ferret post-infection antisera and $\mathrm{HI}$ antibody reactivity, as these tests rely on receptor binding to indicator red cells. The limited data available so far from characterisation of the antigenic profiles of circulating influenza virus strains using virus neutralisation does not reveal major antigenic variation between the various $\mathrm{H}_{3} \mathrm{~N}_{2}$ genetic subgroups. However, it is notable that 3 C.2a2 (subgroup 3) viruses have acquired the 3 C.2a1 neuraminidase (NA) gene through reassortment, which may contribute to overall antigenicity of the emerging dominant $\mathrm{H}_{3} \mathrm{~N}_{2}$ viruses, resulting in a poorer match to the $2017 / 18$ vaccine virus [27]. As the neuraminidase content of vaccines is not standardised, and neuraminidase inhibiting ( $\mathrm{NI}$ ) antibodies in the population are not routinely measured, it is not possible to assess the contribution that this evolutionary change in the
$\mathrm{H}_{3} \mathrm{~N}_{2}$ virus will make to overall population immunity and susceptibility, and therefore VE. This is an area which requires further detailed and systematic study, including an understanding of the contribution of viral neuraminidase to overall viral fitness and immune escape. Natural virus evolution seems to have been exacerbated further by the egg-adaption of the vaccine virus; with the $\mathrm{A}\left(\mathrm{H}_{3} \mathrm{~N}_{2}\right)$ age-specific susceptibility data from summer 2017, showing significantly lower seroreactivity particularly in the elderly for the cell-derived $\mathrm{A}\left(\mathrm{H}_{3} \mathrm{~N}_{2}\right)$ virus compared with the same age group for the egg-grown $\mathrm{A}\left(\mathrm{H}_{3} \mathrm{~N}_{2}\right)$ virus, an observation which has been made elsewhere $[7,28]$. Tissue culture grown vaccine virus strains are considered more representative of the circulating virus strains which are recovered from human respiratory tract [15]. Detailed follow-up investigations of the molecular basis of the differences are required from this observation. However, it does highlight the potential value of seroprevalence surveys to identify possible susceptibility gaps in the population. Further work is required to disentangle the relative contribution of these different factors including 
Antibody seroprevalence levels by age group against (A) A/Hong Kong/4801/2014 virus either grown in tissue culture or propagated in egg or (B) B/Yamagata and B/Victoria viruses, England, United Kingdom, 2016 and 2017 ( $\mathrm{n}=1,741)$

\section{A.}

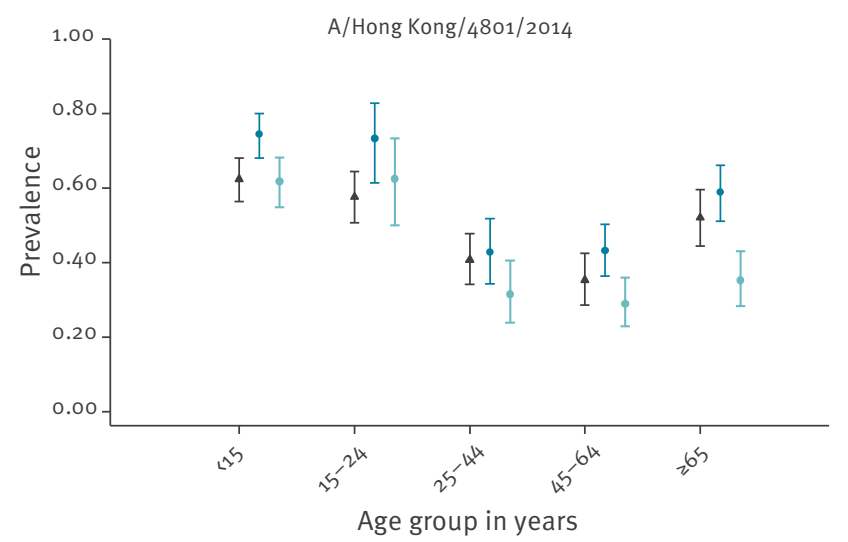

$\begin{array}{ll}\Delta \text { Between } & \text { Between } 2016 / 17 \text { and } \\ 2015 / 16 \text { and } 2016 / 17 & 2017 / 18, H_{3} \text { N2 egg }\end{array}$

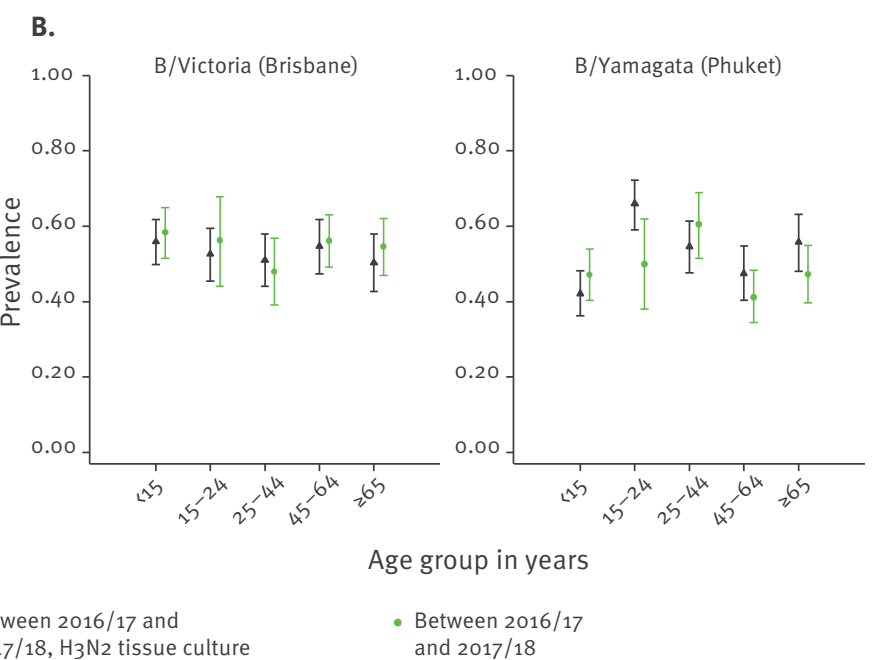

2017/18, H3N2 tissue culture
- Between 2016/17 yearly vaccination and immunosenescence. Though these results support the need for more effective interventions against $A\left(\mathrm{H}_{3} \mathrm{~N}_{2}\right)$, particularly for older people, where the burden of $A\left(\mathrm{H}_{3} \mathrm{~N}_{2}\right)$ is most notable [29], but also children, where the programme is intended to provide both direct protection to the children themselves, and by reducing their rates of infection, indirectly protect others in the population. WHO has recommended that the $\mathrm{A}\left(\mathrm{H}_{3} \mathrm{~N}_{2}\right)$ component of the $2018 / 19$ vaccine is updated to the A/Singapore/INFIMH-16-0019/2016 $\left(\mathrm{H}_{3} \mathrm{~N}_{2}\right)$-like virus and the UK has preferentially recommended adjuvanted vaccine for the elderly in 2018/19, which is likely to enhance and increase the breadth of the immune response against $\mathrm{A}\left(\mathrm{H}_{3} \mathrm{~N}_{2}\right)$. Finally, cellbased influenza vaccines, which avoid the issue of egg-adaption are now being used in North America and are now licensed for use in the UK in 2019/20. Indeed VE results from the $2017 / 18$ season in the US suggest such vaccines offer significantly better protection compared with traditional egg-based, non-high dose vaccines in $\geq 65$ year olds [30].

The present study does report significant LAIV4 effectiveness for children 2-17years of age against influenza $A\left(\mathrm{H}_{1} \mathrm{~N}_{1}\right)$ pdmo9. These results are particularly encouraging in the light of the temporary recommendation to not use $\mathrm{LAIV}_{4}$ in the US following the finding of reduced VE in 2015/16 [5]. The US results of no significant effectiveness against $A\left(\mathrm{H}_{1} \mathrm{~N}_{1}\right)$ pdmog were at odds with those seen in several other countries that had used LAIV4 in 2015/16, including the UK $[6,31$, though all had noted lower effectiveness of $\mathrm{LAIV}_{4}$ against $A\left(H_{1} N_{1}\right)$ pdmog compared with IIV in 2015/16. One emerging hypothesis suggests this might relate to reduced replicative ability of the $A(B o l i v i a / 559 / 2013)$ $\left(\mathrm{H}_{1} \mathrm{~N}_{1}\right)$ pdmog vaccine strain in LAIV4 [31], whereby this strain was updated to the A(Slovenia/2903/2015) $\left(\mathrm{H}_{1} \mathrm{~N}_{1}\right)$ pdmog strain for the $2017 / 18$ season. Recently presented results from the LAIV manufacturer in the US indicate more encouraging shedding and immunogenicity data of this new strain in young children compared with A/Bolivia/559/2013 [32]. The results in this study of good effectiveness against $A\left(\mathrm{H}_{1} \mathrm{~N}_{1}\right)$ pdmog supports the ongoing roll-out of the UK paediatric influenza vaccine programme, although the reduced $\mathrm{A}\left(\mathrm{H}_{3} \mathrm{~N}_{2}\right)$ effectiveness seen this season (due to likely egg-adaption) still needs to be addressed.

In summary, this work demonstrates a lack of significant effectiveness against $\mathrm{A}\left(\mathrm{H}_{3} \mathrm{~N}_{2}\right)$ in all age groups possibly related to several factors most notably eggadaption of the vaccine virus combined with the emergence of a new $\mathrm{A}\left(\mathrm{H}_{3} \mathrm{~N}_{2}\right)$ subgroup. It is hoped that the impact of $A\left(\mathrm{H}_{3} \mathrm{~N}_{2}\right)$ will be mitigated by the updating of the $A\left(H_{3} N_{2}\right)$ vaccine virus strain in 2018/19 and the availability of newly licensed adjuvanted, high-dose and cell-based vaccines in the UK. The result of lower effectiveness of inactivated trivalent vaccine against influenza $B$ in adults seems most likely related to the $B$ lineage mismatch this season. The introduction of quadrivalent influenza vaccine for adults in the UK in $2018 / 19$ is intended to help to improve protection [33]. The VE results for both influenza $B$ and $A\left(\mathrm{H}_{1} \mathrm{~N}_{1}\right)$ pdmo9 in children are encouraging - though the poor performance against $\mathrm{A}\left(\mathrm{H}_{3} \mathrm{~N}_{2}\right)$ this season will need to be monitored carefully.

\section{Acknowledgements}

We are grateful to the many patients of participating practices who consent to virology swabs being taken; to the practices participating in the surveillance schemes in England, Wales, Northern Ireland and Scotland who supplied the clinical information on their patients; to the staff of the PHE Respiratory Virus Unit, the PHE Specialist Microbiology Laboratories, Public Health Wales Specialist Virology Centre, the West of Scotland Specialist Virology Centre and the Regional Virus 
Laboratory, Belfast who undertook analysis of specimens. We thank the staff of PHE, RCGP RSC, Public Health Wales, Public Health Agency Northern Ireland and Health Protection Scotland teams who coordinate the GP schemes, in particular Praveen Sebastian Pillai and Nisha Oppilamany from PHE; Richard Lewis, Ember Hilvers, Caroline Harries and Jana Zitha from PHW; Mark O'Doherty, Emma Walker and Cathriona Kearns from the PHA Catherine Frew, Alasdair MacLean from WoSSVC, Naoma William, Louise Primrose-Shaw, Ross Cameron and the Scottish Health Protection Network Project Team from HPS for overseeing data collection, and Filipa Ferreira, Rachel Byford, Sameera Pathirannehelage, Chris McGee and Mariya Hriskova from RCGP RSC/University of Surrey. We acknowledge the originating and submitting laboratories of the sequences from GISAID's EpiFlu Database on which some of the analyses are based (Supplement). Al submitters of data may be contacted directly via the GISAID website www.gisaid.org.

Funding statement: The study is partly funded from the European Union's Horizon 2020 research and innovation programme under grant agreement No 634446

\section{Conflict of interest}

SL has received university funding for studies of post vaccination adverse events of interest from GSK, and for attitudes to vaccination from Seqirus; and has been a member of Seqirus and Sanofi advisory boards. MD received lecturing fee from Sanofi Pasteur MSD; SpeeDx provided partial financial support for an educational meeting and UK Clinical Virology Network (UK CVN) which he chairs is a registered charity which includes a number of commercial partners. CM has received funding as an advisory board member of Seqirus. No other co-authors had conflicts to declare.

\section{Authors' contributions}

RP led the drafting on behalf of the group; AD, CR, NP and NA led on the statistical analysis; JE, RG, MG, CM, AL, KH and $M Z$ led on the virological analysis; all co-authors (RP, AD, JE, NA, DM, SC, AR, RG, MD, NP, AL, MG, KH, CR, MSa, IY, RW, CM, MSi, SS, JM, SL, MZ) contributed epidemiological and/or virological data, contributed to the design and interpretation of the results; all contributed and reviewed the early drafts and all but RW approved the final version. RW was unavailable to review the final version and give final approval.

\section{References}

1. Hakin $B$, Cosford $P$, Harvey $F$. The flu immunisation programme 2013/14- extension to children. London: Department of Health; 26 Jul 2013. Available from: https://www.gov.uk/government/ uploads/system/uploads/attachment_data/file/225360/ Children s flu letter 2013.pdf

2. Public Health England, Department of Health. Flu Plan Winter. 2017-18. London: NHS England; March 2017. Available from: https://assets.publishing.service.gov.uk/government/uploads/ system/uploads/attachment data/file/600532/annual flu plan_2017t02018.pdf

3. World Health Organization (WHO). WHO recommended composition for 2017/18 Northern hemisphere influenza season. Geneva: WHO; 2 March 2017. Available from: https://www.who.int/influenza/vaccines/virus/ recommendations/2017 18 north/en/

4. Pebody R, Warburton F, Ellis J, Andrews N, Potts A, Cottrell S, et al. Effectiveness of seasonal influenza vaccine for adults and children in preventing laboratory-confirmed influenza in primary care in the United Kingdom: $2015 / 16$ end-of-season results. Euro Surveill. 2016;21(38):30348. https://doi. org/10.2807/1560-7917.ES.2016.21.38.30348 PMID: 27684603

5. Grohskopf LA, Sokolow LZ, Broder KR, Olsen SJ, Karron RA, Jernigan DB, et al. Prevention and Control of Seasonal
Influenza with Vaccines. MMWR Recomm Rep. 2016;65(5):1-54. https://doi.org/10.15585/mmwr.rr6505a1 PMID: 27560619

6. Penttinen PM, Friede MH. Decreased effectiveness of the influenza $\mathrm{A}\left(\mathrm{H}_{1} \mathrm{~N}_{1}\right)$ pdmog strain in live attenuated influenza vaccines: an observational bias or a technical challenge? Euro Surveill. 2016;21(38):30350. https://doi.org/10.2807/15607917.ES.2016.21.38.30350 PMID: 27684999

7. Skowronski DM, Janjua NZ, De Serres G, Sabaiduc S, Eshaghi A, Dickinson JA, et al. Low 2012-13 influenza vaccine effectiveness associated with mutation in the egg-adapted $\mathrm{H}_{3} \mathrm{~N}_{2}$ vaccine strain not antigenic drift in circulating viruses. PLoS One. 2014;9(3):e92153. https://doi.org/10.1371/journal. pone.0092153 PMID: 24667168

8. Public Health England (PHE). Annual National Flu Report: Surveillance of influenza and other respiratory viruses in the UK: Winter 2017 to 2018. London: PHE; May 2018. Available from: https://assets.publishing.service.gov.uk/government/ uploads/system/uploads/attachment_data/file/710483/ Surveillance_of_influenza_and_other_respiratory_viruses_in_ the_UK_2017_to_2018.pdf

9. Fleming DM, Andrews NJ, Ellis JS, Bermingham A, Sebastianpillai $P$, Elliot AJ, et al. Estimating influenza vaccine effectiveness using routinely collected laboratory data. J Epidemiol Community Health. 2010;64(12):1062-7. https://doi. org/10.1136/jech.2009.093450 PMID: 19910645

10. Gunson R, Maclean A, Davies E, Bennett S, Miller R, Carman WF. Development of a multiplex real-time RT-PCR that allows universal detection of influenza $A$ viruses and simultaneous typing of influenza $\mathrm{A} / \mathrm{H}_{1} \mathrm{~N}_{1} / 2009$ virus. J Virol Methods. 2010;163(2):258-61. https://doi.org/10.1016/j. jviromet.2009.10.006 PMID: 19854220

11. Matrosovich M, Matrosovich T, Carr J, Roberts NA, Klenk HD. Overexpression of the alpha-2,6-sialyltransferase in MDCK cells increases influenza virus sensitivity to neuraminidase inhibitors. J Virol. 2003;77(15):8418-25. https://doi. org/10.1128/JVI.77.15.8418-8425.2003 PMID: 12857911

12. Zambon M. Laboratory Diagnosis of Influenza. In: Nicholson K, Hay A, Webster RG, editors. Textbook of Influenza. Oxford: Blackwell Science; 1998. pp. 291-313].

13. Tamura K, Stecher G, Peterson D, Filipski A, Kumar S. MEGA6: Molecular Evolutionary Genetics Analysis version 6.0. Mol Biol Evol. 2013;30(12):2725-9. https://doi.org/10.1093/molbev/ mst197 PMID: 24132122

14. World Health Organization (WHO). Composition recommandée des vaccins antigrippaux pour la saison grippale 2017-2018 dans l'hémisphère Nord. [Recommended composition of influenza virus vaccines for use in the 2017-2018 northern hemisphere influenza season]. Wkly Epidemiol Rec. 2017;92(11):117-28. PMID: 28303704

15. Zost SJ, Parkhouse K, Gumina ME, Kim K, Diaz Perez S, Wilson $\mathrm{PC}$, et al. Contemporary $\mathrm{H}_{3} \mathrm{~N}_{2}$ influenza viruses have a glycosylation site that alters binding of antibodies elicited by egg-adapted vaccine strains. Proc Natl Acad Sci USA. 2017;114(47):12578-83. https://doi.org/10.1073/ pnas.1712377114 PMID: 29109276

16. Rondy M, Kissling E, Emborg HD, Gherasim A, Pebody $R$, Trebbien R, et al. Interim 2017/18 influenza seasonal vaccine effectiveness: combined results from five European studies. Euro Surveill. 2018;23(9):1800086. https://doi. org/10.2807/1560-7917.ES.2018.23.9.18-00086 PMID: 29510782

17. Flannery B, Chung JR, Belongia EA, McLean HQ, Gaglani M, Murthy K, et al. Interim Estimates of 2017-18 Seasonal Influenza Vaccine Effectiveness - United States, February 2018. MMWR Morb Mortal Wkly Rep. 2018;67(6):180-5. https://doi. org/10.15585/mmwr.mm6706a2 PMID: 29447141

18. Skowronski DM, Chambers C, De Serres G, Sabaiduc S, Winter AL, Dickinson JA, et al. Vaccine effectiveness against lineage matched and mismatched influenza $B$ viruses across 8 seasons in Canada, 2010-11 to 2017-18. Clin Infect Dis. 2018;68(10):1754-7. https://doi.org/10.1093/cid/ciy876 PMID: 30312364

19. McLean HQ, Thompson MG, Sundaram ME, Kieke BA, Gaglani $M$, Murthy K, et al. Influenza vaccine effectiveness in the United States during 2012-2013: variable protection by age and virus type. J Infect Dis. 2015;211(10):1529-40. https://doi. org/10.1093/infdis/jiu647 PMID: 25406334

20. de Boer PT, van Maanen BM, Damm O, Ultsch B, Dolk FCK, Crépey $P$, et al. A systematic review of the health economic consequences of quadrivalent influenza vaccination. Expert Rev Pharmacoecon Outcomes Res. 2017;17(3):249-65. https:// doi.org/10.1080/14737167.2017.1343145 PMID: 28613092

21. Thorrington $D$, van Leeuwen $E$, Ramsay $M$, Pebody $R$, Baguelin $M$. Cost-effectiveness analysis of quadrivalent seasonal influenza vaccines in England. BMC Med. 2017;15(1):166 https://doi.org/10.1186/s12916-017-0932-3 PMID: 28882149 
22. Hodgson D, Baguelin M, van Leeuwen E, Panovska-Griffiths J, Ramsay M, Pebody R, et al. Effect of mass paediatric influenza vaccination on existing influenza vaccination programmes in England and Wales: a modelling and cost-effectiveness analysis. Lancet Public Health. 2017;2(2):e74-81. https://doi. org/10.1016/S2468-2667(16)30044-5 PMID: 28299371

23. Pebody R, Warburton F, Ellis J, Andrews N, Potts A, Cottrell $S$, et al. End-of-season influenza vaccine effectiveness in adults and children, United Kingdom, 2016/17. Euro Surveill. 2017;22(44): 1700306. https://doi.org/10.2807/1560-7917. ES.2017.22.44.17-00306 PMID: 29113630

24. Skowronski DM, Chambers C, Sabaiduc S, Dickinson JA, Winter AL, De Serres G, et al. Interim estimates of 2016/17 vaccine effectiveness against influenza $A\left(\mathrm{H}_{3} \mathrm{~N}_{2}\right)$, Canada, January 2017. Euro Surveill. 2017;22(6):30460. https://doi. org/10.2807/1560-7917.ES.2017.22.6.30460 PMID: 28205503

25. Belongia EA, Simpson MD, King JP, Sundaram ME, Kelley NS, Osterholm MT, et al. Variable influenza vaccine effectiveness by subtype: a systematic review and meta-analysis of testnegative design studies. Lancet Infect Dis. 2016;16(8):94251. https://doi.org/10.1016/S1473-3099(16)00129-8 PMID: 27061888

26. Lin Y, Wharton SA, Whittaker L, Dai M, Ermetal B, Lo J, et al. The characteristics and antigenic properties of recently emerged subclade $3 \mathrm{C} .3 \mathrm{a}$ and $3 \mathrm{C} .2 \mathrm{a}$ human influenza $\mathrm{A}\left(\mathrm{H}_{3} \mathrm{~N}_{2}\right)$ viruses passaged in MDCK cells. Influenza Other Respir Viruses. 2017;11(3):263-74. https://doi.org/10.1111/irv.12447 PMID: 28164446

27. World Health Organization (WHO). Recommended composition of influenza virus vaccines for use in the 2018 southern hemisphere influenza season. Geneva: WHO; 28 September 2017. Available from: https://www.who.int/influenza/vaccines/ virus/recommendations/201709_recommendation.pdf?ua $=1$

28. Zost SJ, Parkhouse K, Gumina ME, Kim K, Diaz Perez S, Wilson $\mathrm{PC}$, et al. Contemporary $\mathrm{H}_{3} \mathrm{~N}_{2}$ influenza viruses have a glycosylation site that alters binding of antibodies elicited by egg-adapted vaccine strains. Proc Natl Acad Sci USA. 2017;114(47):12578-83. https://doi.org/10.1073/ pnas.1712377114 PMID: 29109276

29. Shay DK, Chillarige Y, Kelman J, Forshee RA, Foppa IM, Wernecke $M$, et al. Comparative Effectiveness of High-Dose Versus Standard-Dose Influenza Vaccines Among US Medicare Beneficiaries in Preventing Postinfluenza Deaths During 20122013 and 2013-2014. J Infect Dis. 2017;215(4):510-7. https:// doi.org/10.1093/infdis/jiw641 PMID: 28329311

30. Izurieta HS, Chillarige Y, Kelman J, Wei Y, Lu Y, Xu W, et al. Relative effectiveness of cell-cultured and egg-based influenza vaccines among the U.S. elderly, 2017-18. J Infect Dis. 2018. https://doi.org/10.1093/infdis/jiy716 PMID: 30561688

31. Ambrose CS, Bright H, Mallory R. Letter to the editor: Potential causes of the decreased effectiveness of the influenza $A\left(\mathrm{H}_{1} \mathrm{~N}_{1}\right)$ pdmog strain in live attenuated influenza vaccines. Euro Surveill. 2016;21(45):30394. https://doi.org/10.2807/15607917.ES.2016.21.45.30394 PMID: 27918259

32. Mallory R. Results of Randomized Trial of a New $\mathrm{H}_{1} \mathrm{~N}_{1}$ LAIV Strain in US Children. Presentation to ACIP 21 Feb 2018. page 53. Available from: https://www.cdc.gov/vaccines/acip/ meetings/downloads/min-archive/min-2018-02-508.pdf

33. Public Health England, Department of Health. Annual Flu Letter. 2018/19. London: NHS; 26 March 2018. Available from: https://assets.publishing.service.gov.uk/government/ uploads/system/uploads/attachment_data/file/694779/ Annual_national_flu_programme_2018-2019.pdf

\section{License, supplementary material and copyright}

This is an open-access article distributed under the terms of the Creative Commons Attribution (CC BY 4.0) Licence. You may share and adapt the material, but must give appropriate credit to the source, provide a link to the licence and indicate if changes were made.

Any supplementary material referenced in the article can be found in the online version.

This article is copyright of the authors or their affiliated institutions, 2019. 